\title{
Ocean Fronts and Eddies Remotely Forcing Atmospheric Rivers and Heavy Precipitation
}

\section{Xue Liu}

Texas A\&M University

Xiaohui Ma ( $\nabla$ maxiaohui@ouc.edu.cn )

Ocean University of China

\section{Ping Chang}

Texas A\&M University

\section{Yinglai Jia}

Ocean University of China

\section{Dan Fu}

Texas A\&M University https://orcid.org/0000-0001-6423-6117

\section{Guangzhi Xu}

Ocean University of China

\section{Lixin Wu}

Key Laboratory of Physical Oceanography-Institute for Advanced Ocean Studies, Ocean University of China and Qingdao National Laboratory for Marine Science and Technology https://orcid.org/00000002-4694-5531

\section{R. Saravanan}

Texas A\&M University

\section{Christina Patricola}

Lawrence Berkeley National Laboratory https://orcid.org/0000-0002-3387-0307

\section{Article}

Keywords: Ocean fronts, eddies, atmospheric rivers (ARs), extreme precipitation, climate models

Posted Date: October 6th, 2020

DOI: https://doi.org/10.21203/rs.3.rs-82364/v1

License: (c) (i) This work is licensed under a Creative Commons Attribution 4.0 International License. Read Full License 
Version of Record: A version of this preprint was published at Nature Communications on February 24th, 2021. See the published version at https://doi.org/10.1038/s41467-021-21504-w. 


\section{Ocean Fronts and Eddies Remotely Forcing Atmospheric Rivers and Heavy}

\section{Precipitation}

Xue $\mathrm{Liu}^{2,3 \dagger}$, Xiaohui $\mathrm{Ma}^{1,2 \dagger^{*}}$, Ping Chang ${ }^{2,3,4,{ }^{*}}$, Yinglai Jia ${ }^{1,2}$, Dan $\mathrm{Fu}^{2,3}$, Guangzhi Xu ${ }^{1}$, Lixin $\mathrm{Wu}^{1}$, R. Saravanan ${ }^{2,4}$, Christina M. Patricola ${ }^{5}$

1. Key Laboratory of Physical Oceanography/Frontiers Science Center for Deep Ocean Multispheres and Earth System, Ocean University of China and Pilot National Laboratory for Marine Science and Technology, Qingdao, China.

2. International Laboratory for High-Resolution Earth System Prediction, Texas A\&M University, College Station, TX, USA

3. Department of Oceanography, Texas A\&M University, College Station, TX, USA

4. Department of Atmospheric Sciences, Texas A\&M University, College Station, TX, USA

5. Department of Geological and Atmospheric Sciences, Iowa State University, IA, USA

*Correspondence to maxiaohui@,ouc.edu.cn and ping@tamu.edu

${ }^{\dagger}$ These authors contributed equally.

Atmospheric rivers (ARs) are responsible for over $90 \%$ of poleward water vapor transport in the midlatitudes and can produce extreme precipitation when they make landfall $^{1-2}$. However, despite of recent improvements, weather and climate models still have difficulty simulating and predicting the timing and location of landfalling ARs and associated extreme precipitation ${ }^{3-5}$, highlighting the need to better understand AR dynamics. Here, using high-resolution climate models and observations, we demonstrate for the first time that mesoscale sea-surface temperature (SST) anomalies associated with the Kuroshio front and eddies can exert a remote influence on landfalling ARs and related heavy precipitation along the West Coast of North America. Inclusion of the mesoscale SST forcing in the simulations results in 
approximately a $40 \%$ increase in landfalling ARs and up to a $30 \%$ increase in heavy precipitation in mountainous regions. The modeling results further show that this remote impact occurs within two weeks, implying the potential influence of the dynamical processes on AR predictability at subseasonal-to-seasonal time scales. A proposed mechanism for the influence of mesoscale SST forcing on ARs is the asymmetrical response of the atmosphere to warm vs. cold mesoscale SSTs over the eddy-rich Kuroshio Extension region, which results in a net increase of moisture flux above the planetary boundary layer, prompting AR genesis via enhancing moisture transport into extratropical cyclones in the presence of mesoscale SST forcing.

Since the term was coined nearly three decades ago ${ }^{1}$, atmospheric rivers (ARs), which are plumes of intense water vapor transport emanating from the atmospheric moisture pool, have been recognized as one of the most important sources of extreme hydroclimate events in the global extratropics, capable of producing torrential rains and floods when making landfall over regions of elevated orography, such as the West Coast of North America ${ }^{1,6,7}$. Some of the most severe river floods in California were associated with $\mathrm{ARs}^{8}$. A recent global analysis of ARs' role in driving hydrological extremes found that ARs can contribute not only to extreme floods in many major drainage basins, but also to drought occurrence when ARs are inactive ${ }^{9}$. Therefore, developing and improving the capability of predicting ARs at subseasonal-to-seasonal (S2S) time scales, especially landfalling ARs, can have important implications for water resource management, flood control, and drought relief. Though forecasts of overall occurrence and intensity of ARs have been improved in current weather forecast and climate models, the timing and location of landfalling ARs, as well as their precipitation impact, are notoriously difficult to predict $^{3,4,5,10,11}$, underscoring the importance of a better understanding of ARs' dynamics and their predictability sources. A community-driven research effort is currently ongoing to understand and quantify uncertainties in AR science ${ }^{12,13}$. 

variability at $\mathrm{S} 2 \mathrm{~S}$ time scales, such as the Madden-Julian Oscillation (MJO) $)^{14,15}$ and El

Niño-Southern Oscillation (ENSO) $)^{16-18}$. To the best of our knowledge, none of the published studies explore the potential influence of midlatitude mesoscale SSTs induced by fronts and ocean eddies on ARs, despite the fact that these features along major ocean fronts, such as the Kuroshio Extension (KE) and Gulf Stream (GS), are well known for their impact on the overlying atmosphere, as revealed by high-resolution satellite observations and climate model simulations ${ }^{19-24}$. Evidence is also mounting that the influence of mesoscale SSTs can extend beyond the atmospheric boundary layer, affecting extratropical cyclones and midlatitude storm tracks at far distance ${ }^{25-36}$. Given the close association between the occurrence of ARs and extratropical cyclones ${ }^{37-42}$, a natural question to ask is: can mesoscale SSTs influence ARs on S2S time scales, particularly landfalling ARs and associated heavy precipitation events?

To investigate this question, we conducted two ensembles of twin simulations in the North Pacific sector using a regional climate model - the Weather Research and Forecasting (WRF) model with a $27 \mathrm{~km}$ horizontal resolution (Methods). Each of the twinsimulations consists of two nearly identical runs with only difference between them being the SST forcing: the control run (hereafter CTRL) was forced with the high-resolution $\left(0.09^{\circ}\right)$ satellite-based MicroWave InfradRed Optimal Interpolated (MW-IR) $)^{43,44}$ daily SST, whereas the filtered run (hereafter FILT) was forced with the same SST but subject to a lowpass spatial filter to suppress mesoscale features (Methods). The first ensemble was based on a set of boreal-winter (6-month) twin simulations from 2002 to 2014 (hereafter seasonal-ensemble or SE), and the second ensemble was based on a set of twoweek twin experiments for a selection of winter cyclone cases (hereafter cyclone-ensemble or CE). The SE experiment was designed to examine the overall impact of mesoscale SST forcing on ARs over the winter season, whereas the CE experiment was designed to further 
investigate the impact of mesoscale SSTs on ARs during cyclogenesis and development in the KE region. We chose the North Pacific because 1) the largest population exposed to ARs related flood risk is along the West Coast of North America ${ }^{9}$ and 2) the KE front and eddies generate the strongest mesoscale SST variability in North Pacific (Extended Data Fig. 1) and substantially influence the North Pacific storm track ${ }^{45-47}$.

Figure 1a\&b shows the integrated water vapor transport (IVT) averaged over the AR landfalling days in the SE CTRL compared to that derived from the latest European Centre for Medium-Range Weather Forecast (ECMWF) reanalysis (ERA5) ${ }^{48}$. WRF faithfully reproduces the observed landfalling ARs but with a slightly underestimated IVT intensity, due to a higher frequency of landfalling ARs simulated in WRF (Extended Data Fig. 2). Landfalling ARs can produce high precipitation over elevated terrain through orographic lift. This orography-locked precipitation feature appears in the high-resolution dataset based on the Parameter-elevation Regression on Independent Slopes Model (PRISM) ${ }^{49}$, and is reproduced remarkably well by WRF (Extended Data Fig. 3). However, because the PRISM dataset covers only the continental U.S., the following observational analysis uses the satellite-based Global Precipitation Measurement (GPM) dataset ${ }^{50}$ for heavy precipitation events and the ERA5 reanalysis for landfalling ARs. Although the GPM dataset does not have sufficient resolution to resolve the orography-locked precipitation feature shown in PRISM, it does show a high precipitation concentration along the West Coast of North America (Fig. 1f) that corresponds well to the landfalling ARs (Fig. 1b). In fact, the landfalling AR-induced precipitation in GPM shows comparable values to those derived from the SE CTRL (Fig. 1c\&f), both of which are considerably greater than the corresponding winter-mean (Extended Data Fig. 3), indicating that WRF is skillful in simulating AR-related precipitation. However, the probability density function (PDF) of daily precipitation rate averaged over the West Coast of North America (the magenta box in Fig. 1c) shows an overestimation of accumulated precipitation by WRF (Fig. 1d\&g). 
Nevertheless, the fractional contribution (\%) of AR-related precipitation to total precipitation exhibits similar distributions between GPM and WRF (Fig. 1e\&h). These results give confidence that WRF is capable of realistically simulating AR-induced heavy precipitation along the West Coast of North America, thereby providing a basis for further analysis of the influence of mesoscale SST on landfalling ARs and related precipitation statistics.

To understand the relationship between landfalling ARs and heavy precipitation, we selected a subset of landfalling ARs that are concurrent with heavy precipitation events defined as those with daily precipitation rate exceeding the $75^{\text {th }}$ percentile of the areaaveraged daily precipitation over the West Coast of North America. This subset of landfalling ARs and heavy precipitation events is used in the analyses below. We note that the results do not fundamentally change if extreme precipitation events (exceeding $90^{\text {th }}$ percentile of daily precipitation) are used. Figure $2 \mathbf{a} \& \mathbf{b}$ shows the ensemble-mean landfalling AR IVT accumulated over the heavy precipitation days divided by the total number of winter days (150 days) in the SE CTRL and the corresponding value of SE CTRL minus SE FILT, respectively. The reason for using the accumulated rather than averaged IVT is that suppressing of mesoscale SSTs in FILT leads to a significant decrease in both frequency and strength of landfalling ARs. Accumulated IVT takes account of both AR frequency and strength change while averaged IVT undercuts the frequency change. In fact, the total number of landfalling ARs detected in all 65 ensemble members drops from 829 in SE CTRL to 631 in SE FILT. The accumulated IVT of the landfalling ARs is increased by $\sim 40 \%$ in SE CTRL compared to SE FILT (Fig. 2b). Figure 2c\&d shows the accumulated concurrent heavy precipitation divided by the total winter days and the corresponding difference between SE CTRL and SE FILT. As expected, heavy precipitation over high terrain is most significantly affected by the change in landfalling ARs (Fig. 2d). The presence of mesoscale SST forcing results in up to a $30 \%$ increase in 
heavy precipitation (Fig. 2e) due to the increase of landfalling ARs in the region. A further support to this finding comes from an analysis on the relationship between strength of mesoscale SST forcing and strength of landfalling ARs and heavy precipitation response. Because of the shortness of the record, we simply grouped the 13 years (2002-2014) of SE CTRL into two 4-year sets based on the strength of mesoscale SST forcing and compared the landfalling ARs and heavy precipitation between these two sets (Methods). The results show that the set with stronger mesoscale SST forcing produces stronger landfalling AR and precipitation response (Fig. 3).

This modeling result finds support from ERA-Interim reanalysis in which the SST forcing was switched from a $1^{\circ}$ low-resolution to a $0.5^{\circ}$-and-finer high-resolution observation dataset before and after $2002^{51}$ (Methods and Extended Data Fig. 4a). Contrasting the landfalling AR IVT along the West Coast of North America between the periods of 2002-2017 and 1986-2002 indicates an increase of the IVT in the former (Extended Data Fig. 4c\&e). A similar increase is noted when comparing the landfalling AR IVT between ERA-Interim and the latest ERA5 reanalysis product where an even higher resolution SST forcing $\left(0.25^{\circ}\right)$ was employed ${ }^{52}$ from 1979 to 2006 along with a higher model resolution (Methods and Extended Data Fig. 4b, d, f). These observationbased analyses, albeit not a proof, provide supporting evidence for the model findings.

The CE experiment allows us to further address the question of whether mesoscale SST forcing along the KE front is responsible for the change in landfalling ARs and heavy precipitation. The CE ensemble consists of 568 winter cyclone cases selected from the SE CTRL such that they all passed through the KE region (Methods). Therefore, the majority of ARs generated in this experiment are closely related to these cyclones that pass over the mesoscale SST forcing along the KE. Remarkably, despite the short integration period, the landfalling AR IVT is significantly increased in CE CTRL compared to CE FILT (Extended Data Fig. 5), leading to a significant increase in the precipitation amount due to 
the presence of mesoscale SST features (Fig. $4 \mathbf{a} \& \mathbf{b})$. The two-week mean fractional increase of precipitation ( $>40 \mathrm{~mm}$ day $\left.^{-1}\right)$ in CE CTRL compared to CE FILT can reach $15 \%$

(Fig. 4c). More interestingly, the time-evolving pdf of the fractional precipitation change along the West Coast of North America reveals a delayed response: negligible change within the first 4 days, but a significant increase of up to $40 \%$ for the precipitation higher than $40 \mathrm{~mm} \mathrm{day}^{-1}$ afterwards (Fig. $\mathbf{4 d}$ ). This indicates that the influence of mesoscale SST forcing can occur on weekly time scales, thereby potentially affecting the predictability of AR-related heavy precipitation events along the West Coast of North America.

The delayed precipitation response to the mesoscale SST forcing points to a remote forcing mechanism on landfalling ARs that originates in the eddy-rich KE region. We hypothesize that the key process involved in this remote mechanism lies in the strong influence of mesoscale SST features along the KE (Extended Data Fig. 1) on the net moisture supply to the developing cyclones over this region. This effect is particularly strong following each initial cyclone (selected to initialize the twin ensemble runs) passing through the KE region. In the wake of the initial cyclone's cold front, cold and dry air descends over the KE region. Over warm mesoscale SSTs the atmosphere is destabilized, intensifying vertical mixing and resulting a strong upward vertical moisture flux that pumps moisture out of the PBL. Over cold mesoscale SSTs, however, such a moisture pumping does not occur, because the atmosphere is more stable there. As a result, there is a net increase of moisture above the PBL (Fig. 5a\&b). A recent modeling study shows a similar moisture increase when ocean eddy induced SSTs are included in a set of WRF simulations $^{28}$. This increase of moisture supply from the PBL over the KE acts to moisten the precyclone environment for the next developing cyclone. As such, when the next cyclone develops over the KE, the airflow within the warm sector of the cyclone, known as the feeder airstream ${ }^{39}$, can transport more moisture into the cyclone. A branch of this feeder airstream feeds to the warm conveyor belt ascent, contributing to cyclone 
precipitation, while another branch turns away from the cyclone, exporting moisture from the cyclone to form $\mathrm{AR}^{39}$. Thus, the ability of mesoscale SSTs to moisten precyclone environment over the KE region can lead to increase in AR IVT. This mechanism also explains the delayed precipitation response along the West Coast of North America, because the initial cyclone does not produce major differences in ARs and associated heavy precipitation due to the small difference in the precyclone environment between CTRL and FILT during the initial stage.

The impact of mesoscale SSTs on cyclone-related AR IVT generation is revealed by a composite analysis (Fig. 6). Despite of the small differences in intensity and structure of the composite cyclone between CE CTRL and CE FILT (Fig. 6a\&b), there is a significant increase of AR IVT and precipitation in the warm sector of the composite cyclone when mesoscale SSTs are present in CE CTRL (Fig. 6c-f). Since the majority $(>85 \%)$ of ARs is associated with extratropical cyclones in the simulations, we can conclude that the cyclone-related AR IVT difference is largely responsible for the total AR difference, including the landfalling AR difference, between CTRL and FILT. It indicates that the presence of mesoscale SSTs can enhance AR genesis by increasing IVT associated with extratropical cyclones even though cyclone intensity remains unchanged.

The enhanced moisture supply above PBL over the KE region is also observed in ERA-Interim by contrasting the periods between high- and low-resolution SST forcing (Extended Data Fig. 4g\&h). As shown by both WRF and the reanalysis, maximum moisture anomalies carried by the ARs occur at $\sim 800 \mathrm{hPa}$, and in WRF the value is about 10\% higher in CE CTRL than in CE FILT during the first day of ARs (Fig. 5c). This enhanced moisture supply promotes generation of stronger ARs in the region, as shown by the AR genesis PDF (Fig. 5d) that displays a marked shift towards higher IVT values in CE CTRL compared to CE FILT. Since the stronger ARs are more likely to survive the journey across the Pacific, the fractional difference of AR moisture content between $\mathrm{CE}$ 

making landfall along the West Coast of North America and impacting rainfall in the region

(Fig. 5e-h). The time scale associated with this remote mechanism is approximately 4-5 days, consistent with the result in Fig. 4d. This mechanism of enhanced vertical moisture transport by warm mesoscale SSTs is further tested for its robustness by using different PBL schemes in WRF. The results show that all the schemes produce a net increase of water vapor content above the PBL in response to mesoscale SST forcing (Methods and Extended Data Fig. 6). The overall percentage of water vapor increase in WRF experiments is in line with that in ERA-Interim (Extended Data Fig. 4h), indicating the modeling results are not sensitive to WRF PBL physics parameterizations.

The above results are also supported by a similar twin experiment using a highresolution global model - a version of the Community Atmosphere Model (CAM) at 25 $\mathrm{km}$ horizontal resolution with (CTRL) and without (FILT) mesoscale SST forcing in both the KE and Gulf Stream (GS) extension region (Methods). The CAM results not only show a consistent AR and precipitation response with WRF to KE mesoscale SST forcing in the North Pacific, but also reveal an increase in landfalling ARs and precipitation along the European west coast to GS mesoscale SST anomalies (Extended Data Fig. 7). Given differences in model physics and numerics between WRF and CAM, the consistency between these modeling results further points to the robustness of the findings.

Collectively, these numerical simulations and observations support the hypothesis that mesoscale SST forcing associated with oceanic fronts and eddies in western boundary current regions substantially influences landfalling ARs and associated heavy precipitation on S2S time scales. It indicates that the common practice of using non-eddy-resolving monthly SST as forcing in atmosphere-only models can lead to underestimates of ARinduced heavy precipitation, even for high-resolution atmospheric models. Although further prediction experiments are required to quantify the impact of mesoscale SSTs on 
mesoscale forcing in prediction models.

\section{References}

1. Zhu, Y., Newell, R. E. A proposed algorithm for moisture fluxes from atmospheric rivers. Mon Weather Rev 126, 725-735 (1998).

2. Gimeno, L., Nieto, R., Vazquez, M., Lavers, D. A. Atmospheric rivers: a minireview. Front Earth Sci 2, (2014).

3. Wick, G. A., Neiman, P. J., Ralph, F. M., Hamill, T. M. Evaluation of Forecasts of the Water Vapor Signature of Atmospheric Rivers in Operational Numerical Weather Prediction Models. Weather Forecast 28, 1337-1352 (2013).

4. Cordeira, J. M., Ralph, F. M., Martin, A.,\& coauthors. Forecasting atmospheric rivers during CalWater 2015. Bull. Amer. Meteor. Soc. 98 (3): 449-459 (2017).

5. DeFlorio, M. J., Waliser, D. E., Guan, B., Ralph, F. M., Vitart, F. Global evaluation of atmospheric river prediction skill. J Hydrometeorol 19, 409-426 (2018).

6. Ralph, F. M., Neiman, P. J., Wick, G. A. Satellite and CALJET aircraft observations of atmospheric rivers over the eastern north pacific ocean during the winter of 1997/98. Mon Weather Rev 132, 1721-1745 (2004).

7. Leung, L. R., Qian, Y. Atmospheric rivers induced heavy precipitation and flooding in the western U.S. simulated by the WRF regional climate model. Geophys Res Lett 36, (2009).

8. Dettinger, M. D., Ralph, F. M., Das, T., Neiman, P. J., Cayan, D. R. Atmospheric Rivers, Floods and the Water Resources of California. Water-Sui 3, 445-478 (2011).

9. Paltan, H. et al., Global Floods and Water Availability Driven by Atmospheric Rivers. Geophys Res Lett 44, 10387-10395 (2017).

10. Ralph, F. M. et al., Assessment of Extreme Quantitative Precipitation Forecasts and Development of Regional Extreme Event Thresholds Using Data from HMT-2006 and COOP Observers. J Hydrometeorol 11, 1286-1304 (2010).

11. Lavers, D. A., Pappenberger, F., Zsoter, E. Extending medium-range predictability of extreme hydrological events in Europe. Nat Commun 5(5382):1-7 (2014).

12. Shields, C. A. et al. Atmospheric River Tracking Method Intercomparison Project (ARTMIP): Project goals and experimental design. Geosci. Model Dev. 11, 24552474 (2018).

13. Rutz, J. J. et al. The Atmospheric River Tracking Method Intercomparison Project (ARTMIP): Quantifying Uncertainties in Atmospheric River Climatology. Journal of Geophysical Research: Atmosphere 124, 13777-13802 (2019).

14. Guan, B., Waliser, D. E., Molotch, N. P., Fetzer, E. J., Neiman, P. J. Does the Madden-Julian Oscillation Influence Wintertime Atmospheric Rivers and Snowpack in the Sierra Nevada? Mon Weather Rev 140, 325-342 (2012).

15. Mundhenk, B. D., Barnes, E. A., Maloney, E. D., Baggett, C. F. Skillful empirical subseasonal prediction of landfalling atmospheric river activity using the MaddenJulian oscillation and quasi-biennial oscillation. Npj Clim Atmos Sci 1, (2018).

16. Pezzi, L. P., Cavalcanti, I. F. A. The relative importance of ENSO and tropical Atlantic sea surface temperature anomalies for seasonal precipitation over South America: a numerical study. Climate Dynamics 17, 205-212 (2001).

17. Bao, J. W., Michelson, S. A., Neiman, P. J., Ralph, F. M., Wilczak, J. M. Interpretation of enhanced integrated water vapor bands associated with 
extratropical cyclones: Their formation and connection to tropical moisture. Mon Weather Rev 134, 1063-1080 (2006).

18. Payne, A. E., Magnusdottir, G. Dynamics of Landfalling Atmospheric Rivers over the North Pacific in 30 Years of MERRA Reanalysis. $J$ Climate 27, 7133-7150 (2014).

19. Chelton, D. B., Schlax, M. G., Freilich, M. H., Milliff, R. F. Satellite measurements reveal persistent small-scale features in ocean winds. Science 303, 978-983 (2004).

20. Small, R. J. et al., Air-sea interaction over ocean fronts and eddies. Dynam Atmos Oceans 45, 274-319 (2008).

21. Bryan, F. O. et al., Frontal Scale Air-Sea Interaction in High-Resolution Coupled Climate Models. J Climate 23, 6277-6291 (2010).

22. Yu, L., \& Weller, R. A., Objectively analyzed air-sea heat fluxes for the global icefree oceans (1981-2005). Bull. Amer. Meteor. Soc. 88(4), 527-540 (2007).

23. Masunaga, R., Nakamura, H., Miyasaka, T., Nishii, K., \& Tanimoto, Y., Separation of climatological imprints of the Kuroshio Extension and Oyashio fronts on the wintertime atmospheric boundary layer: Their sensitivity to SST resolution prescribed for atmospheric reanalysis. J Climate 28(5), 1764-1787 (2015).

24. Lee, R. W., Woollings, T. J., Hoskins, B. J., Williams, K. D., O’Reilly, C. H., \& Masato, G., Impact of Gulf Stream SST biases on the global atmospheric circulation. Climate dynamics, 51(9-10), 3369-3387 (2018).

25. Ma, X. H. et al., Distant Influence of Kuroshio Eddies on North Pacific Weather Patterns? Sci Rep-Uk 5, (2015).

26. Ma, X. H. et al., Importance of Resolving Kuroshio Front and Eddy Influence in Simulating the North Pacific Storm Track. J Climate 30, 1861-1880 (2017).

27. Kuwano-Yoshida, A., Minobe, S. Storm-Track Response to SST Fronts in the Northwestern Pacific Region in an AGCM. J Climate 30, 1081-1102 (2017).

28. Foussard, A., Lapeyre, G., Plougonven, R. Storm Track Response to Oceanic Eddies in Idealized Atmospheric Simulations. J Climate 32, 445-463 (2019).

29. Frankignoul, C., Sennechael, N., Kwon, Y. O. and Alexander, M. A. Influence of the Meridional Shifts of the Kuroshio and the Oyashio Extensions on the Atmospheric Circulation. J Climate 24, $762-777$ (2011).

30. O'Reilly, C. H. \& Czaja, A. The response of the Pacific storm track and atmospheric circulation to Kuroshio Extension variability. Quarterly Journal of the Royal Meteorological Society, 141, 52-66, (2015).

31. Parfitt, R., Czaja, A., Minobe, S., \& Kuwano - Yoshida, A. The atmospheric frontal response to SST perturbations in the Gulf Stream region. Geophys. Res. Lett., 43(5), 2299-2306 (2016).

32. Parfitt, R., Czaja, A., \& Kwon, Y. O., The impact of SST resolution change in the ERA - Interim reanalysis on wintertime Gulf Stream frontal air - sea interaction. Geophys. Res. Lett., 44(7), 3246-3254 (2017).

33. Piazza, M., Terray, L., Boé, J., Maisonnave, E. \& Sanchez-Gomez, E. Influence of small-scale North Atlantic sea surface temperature patterns on the marine boundary layer and free troposphere: a study using the atmospheric ARPEGE model. Climate Dynamics, 1-19, (2015).

34. Vannière, B., Czaja, A., Dacre, H., \& Woollings, T., A "cold path" for the Gulf Stream-troposphere connection. J Climate, 30(4), 1363-1379 (2017).

35. Sheldon, L., Czaja, A., Vannière, B., Morcrette, C., Sohet, B., Casado, M., \& Smith, D. A 'warm path'for Gulf Stream-troposphere interactions. Tellus A: Dynamic Meteorology and Oceanography, 69(1), 1299397 (2017).

36. Smirnov, D., Newman, M., Alexander, M. A., Kwon, Y. O., \& Frankignoul, C.. Investigating the local atmospheric response to a realistic shift in the Oyashio sea surface temperature front. J Climate, 28(3), 1126-1147 (2015). 
37. Eiras-Barca, J. et al., The concurrence of atmospheric rivers and explosive cyclogenesis in the North Atlantic and North Pacific basins. Earth Syst Dynam 9, 91-102 (2018).

38. Dacre, H. F., Clark, P. A., Martinez-Alvarado, O., Stringer, M. A., \& Lavers, D. A. How do atmospheric rivers form?. Bulletin of the American Meteorological Society, 96(8), 1243-1255 (2015).

39. Dacre, H. F., Martinez-Alvarado, O. \& Mbengue, C. O. Linking atmospheric rivers and warm conveyor belt airflows. Journal of Hydrometeorology, 20(6), 1183-1196 (2019).

40. Eckhardt, S., Stohl, A., Wernli, H., James, P., Forster, C., \& Spichtinger, N.. A 15year climatology of warm conveyor belts. J Climate, 17(1), 218-237 (2004).

41. Zhang, Z., Ralph, F. M. \& Zheng, M. The relationship between extratropical cyclone strength and atmospheric river intensity and position. Geophys. Res. Lett. 46, 18141823 (2019).

42. Payne, A. E. et al. Responses and impacts of atmospheric rivers to climate change. Nature Reviews Earth and Enviroment, 1, 143-157 (2020).

43. Gentemann, C. L., Wentz, F. J., Mears, C. A., Smith, D. K. In situ validation of Tropical Rainfall Measuring Mission microwave sea surface temperatures. Journal of Geophysical Research: Oceans 109, (2004).

44. Gentemann, C. L., Meissner, T., Wentz, F. J. Accuracy of Satellite Sea Surface Temperatures at 7 and $11 \mathrm{GHz}$. IEEE Transactions on Geoscience and Remote Sensing 48, 1009-1018 (2010).

45. Frankignoul, C., Sennechael, N., Kwon, Y. O., Alexander, M. A. Influence of the Meridional Shifts of the Kuroshio and the Oyashio Extensions on the Atmospheric Circulation. J Climate 24, 762-777 (2011).

46. O'Reilly, C. H., Czaja, A. The response of the Pacific storm track and atmospheric circulation to Kuroshio Extension variability. $Q J$ Roy Meteor Soc 141, 52-66 (2015).

47. Small, R. J., Msadek, R., Kwon, Y.-O., Booth, J. F., Zarzycki, C. Atmosphere surface storm track response to resolved ocean mesoscale in two sets of global climate model experiments. Climate Dynamics 52, 2067-2089 (2019).

48. Copernicus Climate Change Service (C3S), ERA5: fifth generation of ECMWF atmospheric reanalyses of the global climate. Copernicus Climate Change Service Climate Data Store (CDS), data of access. https://cds.climate.copernicus.eu/cdsapp\#!/home (2017).

49. Daly, C., Taylor, G., Gibson, W. The PRISM approach to mapping precipitation and temperature. 10th Conference on Applied Climatology, 10-12 (1997).

50. Skofronick-Jackson, G. et al., The Global Precipitation Measurement (Gpm) Mission for Science and Society. B Am Meteorol Soc 98, 1679-1695 (2017).

51. Dee, D. P. et al., The ERA-Interim reanalysis: configuration and performance of the data assimilation system. Q. J. R. Meteorol. Soc. 137, 553-597 (2011).

52. Hirahara, S., Alonso-Balmaseda, M., de Boisseson, E., Hersbach, H., Sea Surface Temperature and Sea Ice Concentration for ERA5. ERA Report Series, 26 (2016).

\section{Acknowledgments}

This research is supported by the Natural Science Foundation of China 41776013 and U.S. National Science Foundation Grant AGS-1462127, National Key R\&D Program of China (2017YFC1404100, 2017YFC1404101). Y.J. acknowledges the support from the Natural Science Foundation of China (41975065). X.L. acknowledges the support from the China Scholarship Council. C.M.P. acknowledges support from the U.S. Department of Energy, Office of Science, Office of Biological and Environmental Research, Climate and Environmental Sciences Division, Regional \& Global Climate Modeling Program, under 
Award Number DE-AC02-05CH11231. We thank the Texas A\&M Supercomputing Facility and the Texas Advanced Computing Center (TACC), the Center for High Performance Computing and System Simulation at Qingdao Pilot National Laboratory for Marine Science and Technology (QNLM) for providing high performance computing resources that contributed to the research results reported in this paper. This is a collaborative project between the Ocean University of China (OUC), Texas A\&M University (TAMU) and the National Center for Atmospheric Research (NCAR) and completed through the International Laboratory for High Resolution Earth System Prediction (iHESP) - a collaboration among QNLM, TAMU and NCAR.

\section{Author Contributions}

X. L. and X. M. made equal contribution to the model simulations and data analyses. X. L. conducted and analyzed the prediction ensemble simulations, while X. M. conducted and analyzed the seasonal ensemble simulations. Additionally, X. M. carried out the observed AR and precipitation analyses. X. L. conducted the extropical cyclones related analyses. P. C. conceived the original idea and provided interpretations of the results. P. C., X. M. and $\mathrm{X}$. L. co-directed the research and co-wrote the manuscript. Y. J. conducted and analyzed the global CESM simulations. D. F. and G. X. assisted with AR tracking. All authors contributed to improving the manuscript.

\section{Author Information}

Reprints and permissions information is available at www.nature.com/reprints. The authors declare no competing financial interests. Readers are welcome to comment on the online version of the paper. Correspondence and requests for materials should be addressed to X.M. (maxiaohui@ouc.edu.cn) and P.C. (ping@tamu.edu).

\section{Figure Legends}

Figure 1 | Landfalling ARs and concurrent precipitation along the west coast of North America. Averaged IVT $\left(\mathrm{kg} \cdot \mathrm{m}^{-1} \mathrm{~s}^{-1}\right)$ associated with landfalling ARs simulated in SE CTRL (a) and in ERA5 (1979-2017) (b) during the winter season (NDJFM). Averaged precipitation ( $\mathrm{mm} \mathrm{day}^{-1}$ ) associated with landfalling ARs simulated in SE CTRL (c) and in GPM (2014-2016) (f) during the winter season (NDJFM). PDFs of daily precipitation (averaged in the magenta box in Fig. 1c) for all precipitation events (histogram) and those concurrent with landfalling ARs (red line) in SE CTRL (d) and in GPM (g), respectively. PDFs of fraction contribution (\%) of AR-related precipitation to total precipitation in SE CTRL (e) and in GPM (h), respectively. Averaged IVT (precipitation) is computed as the sum of IVT (precipitation) associated with landfalling ARs divided by the total number of landfalling ARs days.

Figure 2 | Response of landfalling ARs and heavy precipitation to mesoscale SSTs in the seasonal ensemble experiment. Landfalling AR IVT $\left(\mathrm{kg} \cdot \mathrm{m}^{-1} \mathrm{~s}^{-1}\right)$ summed over the heavy precipitation days and then divided by the total number of days (150x65) in SE CTRL (a) and the corresponding difference between SE CTRL and FILT (b). c and d, same as $\mathbf{a}$ and $\mathbf{b}$, but for precipitation $\left(\mathrm{mm} \mathrm{day}^{-1}\right)$. PDF of relative difference of precipitation concurrent with landfalling ARs between SE CTRL and FILT in reference to SE CTRL (the red curve in Fig. 1) (e). Heavy precipitation events are defined as area-averaged (magenta box in Fig. 1c) daily precipitation events exceeding the $75^{\text {th }}$ percentile of the value. The difference above $95 \%$ confidence level based on a two-sided student t-test is shaded by gray dots.

Figure 3 | Relationship between ARs/precipitation response strength and SST forcing strength in the seasonal ensemble. $\mathbf{a}$ and c, same as Fig. $\mathbf{2 b}$ and $\mathbf{2 d}$, but for four strong mesoscale SST forcing cases. $\mathbf{b}$ and $\mathbf{d}$, same as Fig. $\mathbf{2 b}$ and $\mathbf{2 d}$, but for four weak mesoscale SST forcing cases.

Figure 4 | Response of heavy precipitation along west coast of North America to mesoscale SST forcing in the cyclone ensemble. Two-week mean heavy precipitation 
$\left(\mathrm{mm}\right.$ day $^{-1}$ ) associated with landfalling ARs in CE CTRL (a) and the corresponding difference between CE CTRL and FILT (b). Two-week mean (c) and time evolving (d) PDF of relative difference of 6-hourly precipitation (averaged in the magenta box in Fig. 1c) concurrent with landfalling ARs between CE CTRL and FILT in reference to CE CTRL. The mean precipitation is computed as the sum of landfalling AR induced precipitation over the heavy precipitation days divided by the two-week simulation period. The difference above $95 \%$ confidence level based on a two-sided student t-test is shaded by gray dots.

Figure 5 | Mechanism of Kuroshio mesoscale SST forcing ARs. Percentage difference of two-week mean water vapor mixing ratio (Q) at $800 \mathrm{hPa}$ between CE CTRL and FILT relative to CE CTRL (a). Difference of two-week mean water vapor mixing ratio $(\mathrm{Q}, \mathrm{kg} / \mathrm{kg})$ along the Kuroshio extension (dashed line in a) between CE CTRL and FILT (b). The heavy line at the bottom of (b) indicates warm (red) and cold (blue) mesoscale SST anomalies. Vertical profile of daily-mean $\mathrm{Q}$ anomalies $(\mathrm{kg} / \mathrm{kg})$ carried by all the ARs within each daily interval, 0-1 day (blue), 1-2 day (red), 2-3 day (yellow) and 3-4 day (purple) following ARs' evolution in CE CTRL (solid lines) and the corresponding fractional difference between CE CTRL and FILT relative to CE CTRL (dashed lines) (c). The thick black line shows the vertical profile of daily mean Q anomalies carried by all ARs detected in ERA5 averaged over 10 boreal winter seasons (NDJFM) from 2008 to 2017. PDFs of ARs when they are first formed in CE CTRL (blue) and FILT (red) (d). Daily mean IVT $\left(\mathrm{kg} \cdot \mathrm{m}^{-1} \mathrm{~s}^{-1}\right)$ of all ARs detected within each daily interval, 0-1 day (e), 1-2 day (f), 2-3 day (g) and 3-4 day (h) following ARs' evolution in CE CTRL. The daily mean values in (c) and (e-h) are all derived from 6-hourly model output. The daily mean $Q$ anomalies in (c) are computed as the sum of area accumulated Q anomalies within ARs detected on corresponding days divided by the total number of corresponding days. The daily mean IVT in (e-h) is computed as the sum of IVT of all ARs detected on corresponding days divided by the total number of corresponding days. The difference above $95 \%$ confidence level based on a two-sided student $t$-test is shaded by gray dots.

Figure 6 | Composite of extratropical cyclones in the cyclone ensemble experiment. Composite of SLP (contours, $\mathrm{hPa}$ ) and $925 \mathrm{hPa}$ wind (vector, $\mathrm{ms}^{-1}$ ) of all identified extratropical cyclones in CE CTRL (a), and the corresponding differences between CE CTRL and FILT (b). The black dot indicates the center of composite cyclone. $\mathbf{c}$ and $\mathbf{d}$, same as a and $\mathbf{b}$, but for composite of AR IVT $\left(\mathrm{kg} \cdot \mathrm{m}^{-1} \mathrm{~s}^{-1}\right)$ associated with extratropical cyclones. e and $\mathbf{f}$, same as $\mathbf{a}$ and $\mathbf{b}$, but for composite of AR-induced precipitation (mm day $^{-1}$ ). The difference above $95 \%$ confidence level based on a two-sided student t-test is shaded by gray dots.

\section{Methods}

\section{Seasonal Ensemble}

The Weather Research and Forecasting (WRF) model $^{53}$ was configured over the North Pacific $\left(\left[3.6^{\circ} \mathrm{N} 66^{\circ} \mathrm{N}\right],\left[99^{\circ} \mathrm{E} 270^{\circ} \mathrm{E}\right]\right)$ with $27 \mathrm{~km}$ horizontal resolution and 30 vertical levels. The initial and lateral boundary conditions were derived from 6-hourly NCEP-DOE AMIP-II reanalysis (NCEP-II $)^{54}$. The experiment contains 13 boreal winter twin simulations from 2002 to 2014, each of which has an ensemble of 5 CTRL and FILT runs, respectively, initialized on October 1 with slightly different states and integrated for 6 
months. The total ensemble size is 65 winter seasons for each of the twin simulations. The low-pass spatial filter applied to the daily SST forcing in the FILT ensemble is a 2-D Loess filter with a $15^{\circ} \times 5^{\circ}$ cut-off wavelength ${ }^{55}$. Only the last 5 months were analyzed, with the first month disregarded as model spin-up. Detailed parameterization schemes used in the model configuration follow a previous study ${ }^{25}$.

\section{Cyclone Ensemble}

The same WRF model configuration was used for this set of twin simulations. A total of 568 winter cyclone cases that pass through the KE region were selected from the SE CTRL. A pair of 14-day simulations - one CTRL and one FILT - were made for each cyclone case, initialized with the restart file and lateral boundary conditions from SE CTRL, but different SST forcing. CE CTRL uses the original SST from SE CTRL, but the SST in CE FILT is subject to the same Loess filter used for SE FILT.

\section{PBL Sensitivity Experiments}

The same WRF model with different PBL and surface-layer schemes was configured to test the sensitivity of water vapor response to different physics parameterizations. The sensitive experiments contain 4 twin simulations in 2007/8 winter season, each of which has an ensemble of 10 CTRL and FILT runs, respectively. Based on previous studies ${ }^{25}, 10$ ensemble members are sufficient to identify a significant atmospheric response to mesoscale SST forcing in WRF because the use of identical lateral boundary conditions acts to reduce the atmospheric internal variability. All the settings in these experiments were the same as WRF SE except that different PBL and surface layer schemes were used, including YSU, MYNN, UW PBL with MM5 surface layer scheme, MYJ PBL with Eta surface layer scheme ${ }^{53}$.

\section{Global Ensemble}

The global climate model used is a version of the Community Atmospheric Model Version 5 (CAM5) at $0.23^{\circ}$ horizontal resolution with prescribed SST and sea ice derived 
WRF design, the global CAM simulations contain 13 boreal winter twin simulations from 2002 to 2014, each of which only has an ensemble of 2 CTRL and FILT runs, respectively, initialized on December 1 with slightly different states and integrated for 3 months. In CTRL, the $0.25^{\circ}$ OISSTV2 was retained. In FILT, a $5^{\circ} \times 5^{\circ}\left(4^{\circ} \times 4^{\circ}\right)$ boxcar lowpass filter was applied to OISSTV2 in the Kuroshio (Gulf Stream) extension region, respectively. The different filtering window width is based on the typical length scale of mesoscale SSTs in these two regions ${ }^{56-58}$.

\section{ARs Detection and Tracking}

To identify and track ARs, we adopted a widely-used AR detection approach ${ }^{2}$ that searches for long narrow region of IVT anomalies of values exceeding a threshold and IVT anomalies are referred to temporal mean ${ }^{59,60}$. Specifically, ARs are identified as continuous areas of IVT $\left(\frac{1}{g} \int_{1000 h P a}^{300 h P a}|\vec{V} Q| d p\right)$ anomalies that exceed $250 \mathrm{kgm}^{-1} \mathrm{~s}^{-1}$, where $\vec{V}$ is winds and $\mathrm{Q}$ is water vapor mixing ratio. For SE, the anomalies were derived from daily mean IVT subtracting climatological winter season (NDJFM) mean of all 65 ensemble members. For CE, the anomalies were derived from 6-hourly IVT subtracting two-week mean of all 568 ensemble members. For the global CAM simulations, the anomalies were derived from daily mean IVT subtracting winter season (DJF) mean of all ensemble members. The outer edge of an AR is defined by a closed IVT contour of $250 \mathrm{kgm}^{-1} \mathrm{~s}^{-1}$. The length of an AR must be longer than $2000 \mathrm{~km}$ while its width must be narrower than $1000 \mathrm{~km}$. ARs were designated as landfalling if the outmost contour insects coastline. The center of an AR is defined as the geometric center of the IVT contour. Coherent AR object is stitched from a Lagrangian tracking approach ${ }^{61}$ to form an AR trajectory. We tested a different AR detection algorithm using integrated water vapor and the tracking results by including or not including a temporal requirement that tracked ARs must last for at least $18 \mathrm{~h}$, the results showed no significant effects on the conclusion of this study. 


\section{Definition of Heavy Precipitation Events}

Heavy precipitation events along the west coast of North America are defined as areaaveraged (magenta box in Fig. 1c) daily precipitation events exceeding the $75^{\text {th }}$ percentile daily precipitation rate. To test the robustness of the results, the analysis was repeated using extreme precipitation events (exceeding $90^{\text {th }}$ percentile daily precipitation rate) and results consistently show higher precipitation associated with landfalling ARs in SE CTRL than FILT. Heavy precipitation events were used because it allows for a larger sample size, increasing the robustness of the results.

\section{Relationship Between ARs/Precipitation Response Strength and Mesoscale SST}

\section{Forcing Strength}

ARs/Precipitation response - mesoscale SST forcing relationship is examined by first dividing the 13 years (2002-2014) of SE simulations into two sets based on the strength of mesoscale SST forcing and then contrasting ARs/Precipitation responses between the two sets. The strength of mesoscale SST forcing is measured by area-averaged mesoscale SST anomaly variance in the Kuroshio extension region $\left(\left[20^{\circ} \mathrm{N} 45^{\circ} \mathrm{N}, 120^{\circ} \mathrm{E}-180^{\circ} \mathrm{E}\right]\right)$. The set with strong (weak) mesoscale SST forcing includes top 4 highest (lowest) mesoscale SST variance winters with a total of 20 ensemble members. The differences of landfalling ARs IVT and precipitation between the two sets are shown in Fig. 3.

\section{Comparison of ARs and Water Vapor in ERA-Interim and ERA5}

The SST forcing in ERA-I was switched from low resolution $\left(1^{\circ}\right)$ to high resolution $\left(0.5^{\circ}\right.$ and finer $)$ before and after 2002, while SST in ERA5 has an even higher resolution of $0.25^{\circ}$ from 1979 to $2006^{51,52}$. Comparison of ERA-I before and after 2002 is similar to the comparison between SE CTRL and FILT, but based on two 16-year periods of 19862001 and 2002-2017. For ERA-I and ERA5 comparison, the period of 1979-2006 was used.

\section{Extratropical Cyclones (EC) Detection and EC/AR Composite}


Centers of ECs were first identified by sea level pressure (SLP) minima within a closed contour, with an additional requirement of at least $1 \mathrm{hPa}$ increase of SLP within $5^{\circ}$ of the center. $400 \mathrm{hPa}$ temperature was used to detect and eliminate those with a warm core so that the identified ECs are distinct from tropical cyclones. Candidates are then stitched in time to form paths, with a maximum distance of $6^{\circ}$ between them. The identified ECs must have a during of at least 2 days and a traveling distance of $10^{\circ}$. Following a recent study ${ }^{63}$, if both an AR and an EC co-exist within a $4000 \mathrm{~km} \times 4000 \mathrm{~km}$ box centered at EC center, the related field including SLP, IVT and precipitation are used in the composite analysis. The detection of extratropical cyclones and composite analysis were performed in the whole North Pacific region $\left(\left[150^{\circ} \mathrm{E}-240^{\circ} \mathrm{E}, 20^{\circ} \mathrm{N}-60^{\circ} \mathrm{N}\right]\right)$.

\section{Significance Test}

A student t-test is applied for a given variable when comparing the difference between CTRL and FILT, assuming each of the detected ARs is an independent sample. Data value in regions without ARs occurrence is set to zero.

\section{Data}

SST and lateral boundary conditions were prescribed to WRF from the daily satellite microwave and infrared (MWIR) SST (http://www.remss.com/measurements/seasurface-temperature) and 6-hourly NCEP-DOE AMIP-II reanalysis (https://www.esrl.noaa.gov), respectively. Observed ARs were derived from the European Centre for Medium-Range Weather Forecasts (ECMWF) ERA-Interim and ERA5 reanalysis (https://www.ecmwf.int/en/forecasts/datasets). Rainfall derived from Parameter-elevation Regression on Independent Slopes Model (PRISM, http://www.prism.oregonstate.edu) and Global Precipitation Measurement (GPM) satellite observations (https://www.nasa.gov/mission_pages/GPM/main/index.html) were used to 
compare with WRF simulations. The model output data in this study are available from the

corresponding authors upon request.

\section{Code Availability}

Atmospheric Model (CAM) are developed by the National Center for Atmospheric

Research (NCAR). Model code is available at (https://www.mmm.ucar.edu/weatherresearch-and-forecasting-model and http://www.cesm.ucar.edu).

\section{References}

53. Skamarock, W. C. et al., A description of the Advanced Research WRF version 3. NCAR Tech. Note TN-4751STR, doi:10.5065/D68S4MVH (2008).

54. Kanamitsu, M. et al., NCEP-DOE AMIP-II reanalysis (R-2). B Am Meteorol Soc 83, 1631-1643 (2002).

55. Schlax, M. G., Chelton, D. B. Frequency-Domain Diagnostics for Linear Smoothers. J Am Stat Assoc 87, 1070-1081 (1992).

56. Putrasahan, D. A., Miller, A. J., Seo, H. Isolating mesoscale coupled oceanatmosphere interation in the Kuroshio Extension region. Dynamics of Atmospheres and Oceans 63, 60-78 (2013).

57. Sugimoto, S. et al., Local atmospheric response to warm mesoscale eddies in the Kuroshio-Oyashio Confluence region. Sci Rep 7, (2017).

58. Eden, C. Eddy length scales in the North Atlantic Ocean. Journal of Geophysical Research: Oceans 112, (2007).

59. Lora, J. M., Mitchell, J. L., Risi, C., Tripati, A. E., North Pacific Atmospheric Rivers and Their Influence on Western North Americ at the Last Glacial Maximum. Geophys Res Lett 44, 1051-1059 (2017).

60. Mundhenk, B. D., Barnes, E. A., Maloney, E. D., All-Season Climatology and Variability of Atmospheric River Frequencies over the North Pacific. J Climate 29, 4885-4903 (2016).

61. Gershunov, A. et al., Assessing the climate-scale variability of atmospheric rivers affecting western North America. Geophys Res Lett 44, 7900-7908 (2017).

62. Ullrich, P.A. and C.M. Zarzycki, TempestExtremes v1.0: A framework for scaleinsensitive pointwise feature tracking on unstructured grids. Geosci. Model. Dev. 10, pp. 1069-1090 (2017).

63. Zhang, Z. et al., The relationship between extropical cyclone strength and atmospheric river intensity and position. Geophys Res Lett 46, 1814-1823 (2017).

\section{Extended Data Figure Legends}

Extended Data Figure 1 | Mesoscale SST forcing in SE and CE simulations. Variance of SST $\left({ }^{\circ} \mathrm{C}^{2}\right)$ difference between SE CTRL and FILT for all 13 winter seasons (2002-2014 NDJFM) (a). Mean SST $\left({ }^{\circ} \mathrm{C}\right)$ difference between CE CTRL and FILT for all 568 cyclone cases $(\mathbf{b})$.

Extended Data Figure 2 | Simulated and observed landfalling ARs occurrence frequency. Frequency (\%) of landfalling ARs in SE CTRL (a) and in ERA5 (1979-2017) 
during boreal winter season (NDJFM) (b). The frequency is defined as the number of days when landfalling ARs occur divided by the total number of winter season days.

Extended Data Figure 3 | Simulated and observed winter precipitation over the western US. Winter season mean (NDJFM) precipitation ( $\mathrm{mm} \mathrm{day}^{-1}$ ) in SE CTRL (a) and in PRISM (1981-2017) (b). Daily precipitation PDFs (averaged in the magenta box in Extended Fig. 3c) in SE CTRL (c) and in PRISM (d).

Extended Data Figure 4 | Response of landfalling ARs and water vapor to mesoscale SST forcing in ERA-Interim and ERA5. Variance of SST $\left({ }^{\circ} \mathrm{C}^{2}\right)$ difference between the $0.5^{\circ}$-and-finer SST forcing period (2002-2017) and the $1^{\circ} \mathrm{SST}$ forcing period (1986-2001) in ERA-Interim (a). Accumulated IVT $\left(\mathrm{kg} \cdot \mathrm{m}^{-1} \mathrm{~s}^{-1}\right)$ associated with landfalling ARs averaged in winter season (NDJFM) during the high-resolution SST forcing period (20022017) (c) and the corresponding difference between high-resolution SST forcing period (2002-2017) and low-resolution SST forcing period (1986-2001) in ERA-Interim (e). b, d, $\mathbf{f}$, as for a, $\mathbf{c}, \mathbf{e}$, but for the difference between ERA5, where higher resolution $\left(0.25^{\circ}\right) \mathrm{SST}$ forcing was used, and ERA-Interim during the period of 1979-2006. Difference of Q $(\mathrm{g} / \mathrm{kg})$ at $800 \mathrm{hPa}(\mathrm{g})$ and fractional difference of Q (\%) along a vertical section of the $\mathrm{KE}\left(35^{\circ} \mathrm{N}\right)$ (h) between high-resolution SST forcing period (2002-2017) and low-resolution SST forcing period (1986-2001) in ERA-Interim. Landfalling AR IVT in c-f is computed as the sum of IVT associated with landfalling ARs divided by the total number of all winter season days in ERA-Interim and ERA5, respectively.

Extended Data Figure 5 | Response of heavy precipitation associated landfalling ARs to mesoscale SST forcing in the cyclone ensemble experiment. Landfalling AR IVT $\left(\mathrm{kg} \cdot \mathrm{m}^{-1} \mathrm{~s}^{-1}\right)$ accumulated over the heavy precipitation days averaged over the two-week period in CE CTRL (a) and the corresponding difference between CE CTRL and FILT (b). Landfalling AR IVT is calculated the same as that in Fig. 2a.

Extended Data Figure 6 | Sensitivity of Water Vapor Response to Different PBL and Surface Layer Schemes in WRF Sensitivity Ensemble Simulations. Fractional difference (\%) of the vertical profile of winter season mean (NDJFM) Q averaged in AR genesis region $\left(\left[25^{\circ} \mathrm{N}-35^{\circ} \mathrm{N} 130^{\circ} \mathrm{E}-150^{\circ} \mathrm{E}\right]\right)$ between CTRL and FILT in reference to CTRL of WRF sensitivity experiments with different PBL and surface layer schemes. All the results are based on the ensemble mean of $102007 / 8$ winter-season runs in each sensitivity experiment.

Extended Data Figure 7 | Response of landfalling ARs to mesoscale SST forcing from global CAM ensemble simulations. Averaged IVT $\left(\mathrm{kg} \cdot \mathrm{m}^{-1} \mathrm{~s}^{-1}\right)$ associated with landfalling ARs in boreal winter months (DJF) in the CTRL (a) and the corresponding difference between the CTRL and FILT (c). b and $\mathbf{d}$, same as $\mathbf{a}$ and $\mathbf{c}$, but for precipitation (mm day${ }^{1}$ ). Averaged IVT (precipitation) is computed as the sum of IVT (precipitation) associated with landfalling ARs divided by the total number of winter month days in global CAM ensemble. 

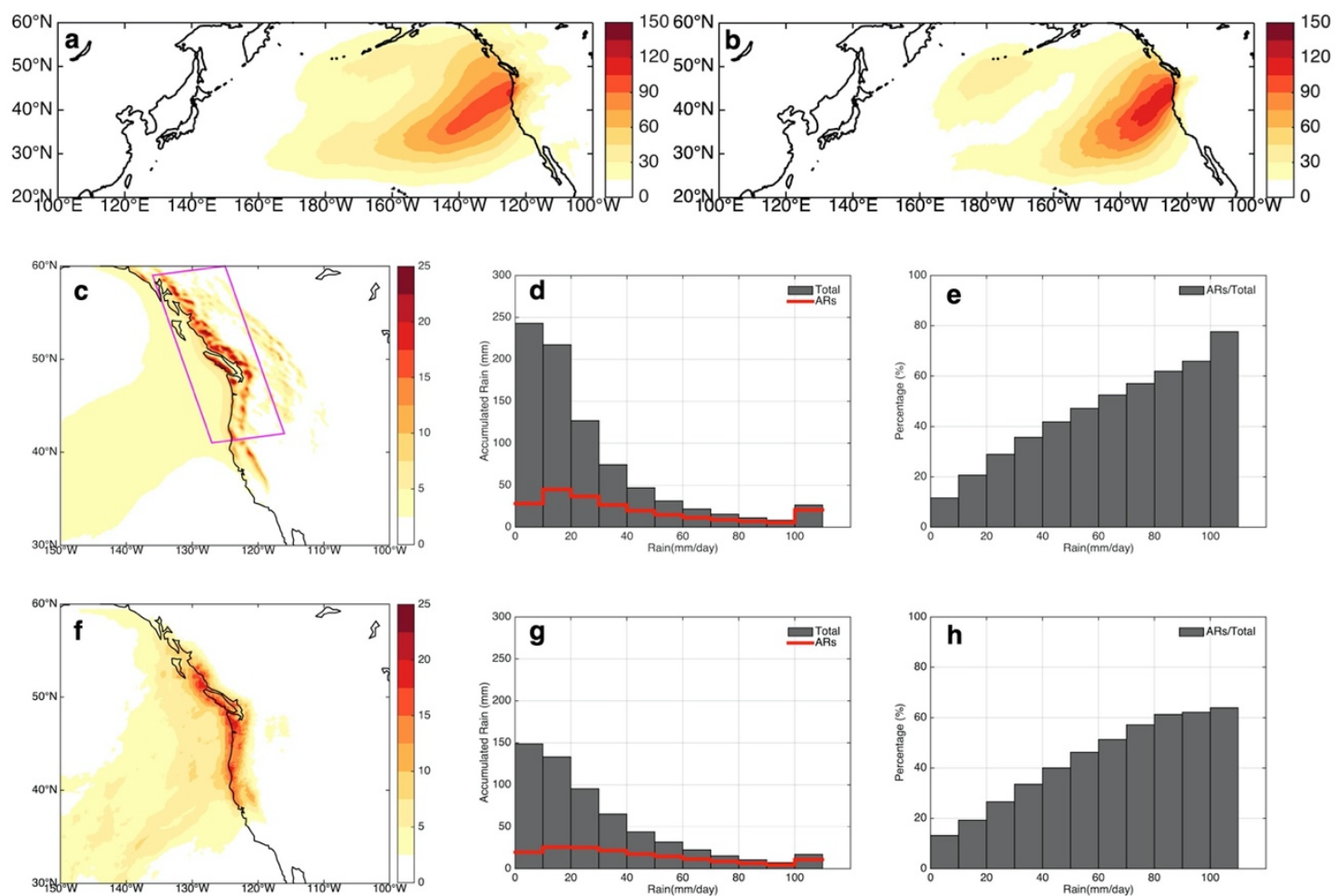

Figure 1 | Landfalling ARs and concurrent precipitation along the west coast of North

America. Averaged IVT $\left(\mathrm{kg} \cdot \mathrm{m}^{-1} \mathrm{~s}^{-1}\right)$ associated with landfalling ARs simulated in SE

CTRL (a) and in ERA5 (1979-2017) (b) during the winter season (NDJFM). Averaged precipitation (mm day ${ }^{-1}$ ) associated with landfalling ARs simulated in SE CTRL (c) and in GPM (2014-2016) (f) during the winter season (NDJFM). PDFs of daily precipitation (averaged in the magenta box in Fig. 1c) for all precipitation events (histogram) and those concurrent with landfalling ARs (red line) in SE CTRL (d) and in GPM (g), respectively. PDFs of fraction contribution (\%) of AR-related precipitation to total precipitation in SE CTRL (e) and in GPM (h), respectively. Averaged IVT (precipitation) is computed as the sum of IVT (precipitation) associated with landfalling ARs divided by the total number of landfalling ARs days. 

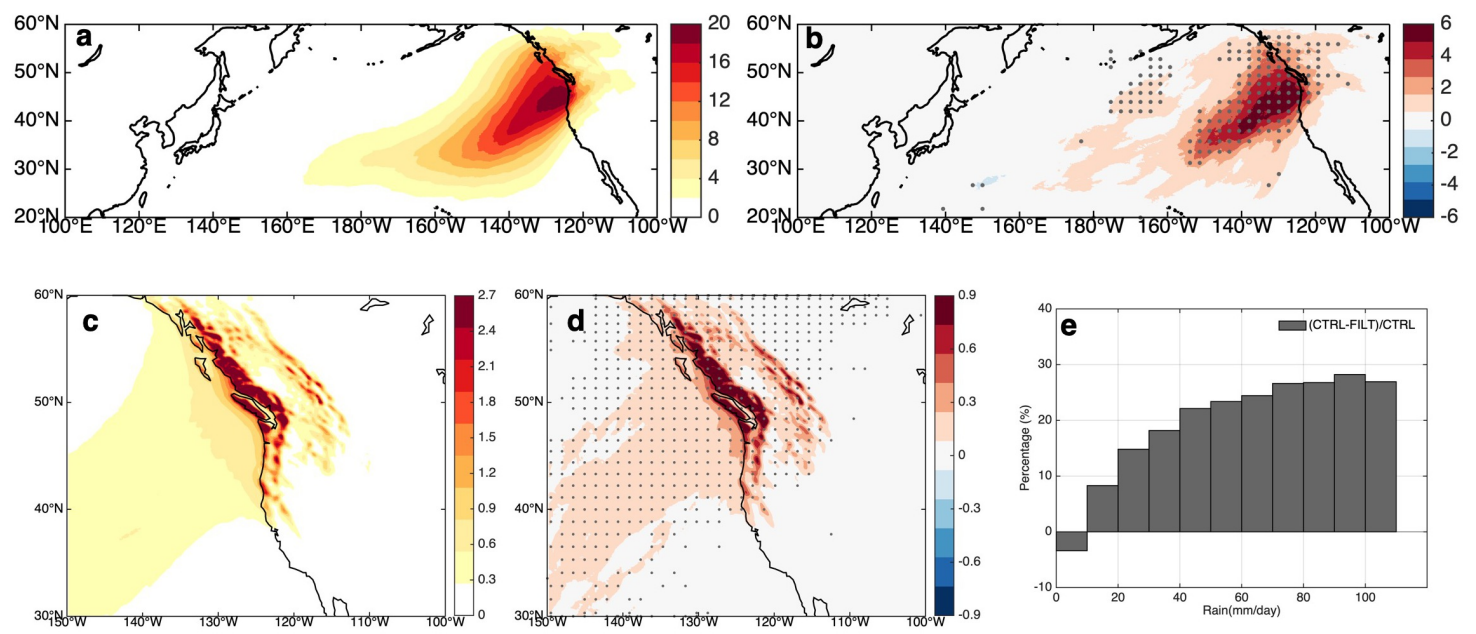

Figure 2 | Response of landfalling ARs and heavy precipitation to mesoscale SSTs in

the seasonal ensemble experiment. Landfalling AR IVT $\left(\mathrm{kg} \cdot \mathrm{m}^{-1} \mathrm{~s}^{-1}\right)$ summed over the heavy precipitation days and then divided by the total number of days (150x65) in SE CTRL (a) and the corresponding difference between SE CTRL and FILT (b). $\mathbf{c}$ and $\mathbf{d}$, same as $\mathbf{a}$ and $\mathbf{b}$, but for precipitation ( $\mathrm{mm}$ day $^{-1}$ ). PDF of relative difference of precipitation concurrent with landfalling ARs between SE CTRL and FILT in reference to SE CTRL (the red curve in Fig. 1) (e). Heavy precipitation events are defined as area-averaged (magenta box in Fig. 1c) daily precipitation events exceeding the $75^{\text {th }}$ percentile of the value. The difference above $95 \%$ confidence level based on a two-sided student $t$-test is shaded by gray dots. 

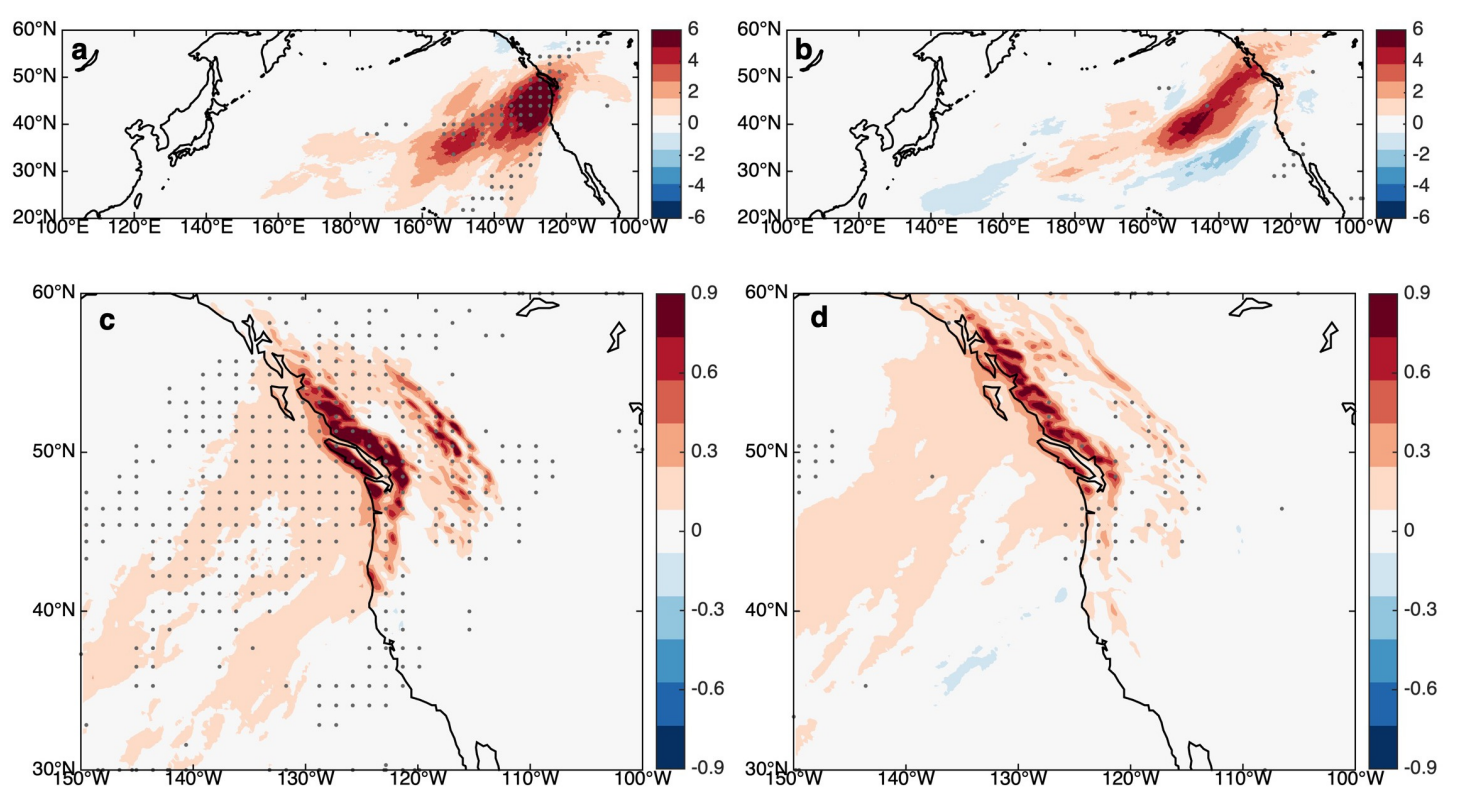

Figure 3 | Relationship between ARs/precipitation response strength and SST forcing

strength in the seasonal ensemble. $\mathbf{a}$ and $\mathbf{c}$, same as Fig. $\mathbf{2 b}$ and $\mathbf{2 d}$, but for four strong mesoscale SST forcing cases. b and $\mathbf{d}$, same as Fig. $\mathbf{2 b}$ and $\mathbf{2 d}$, but for four weak mesoscale SST forcing cases. 

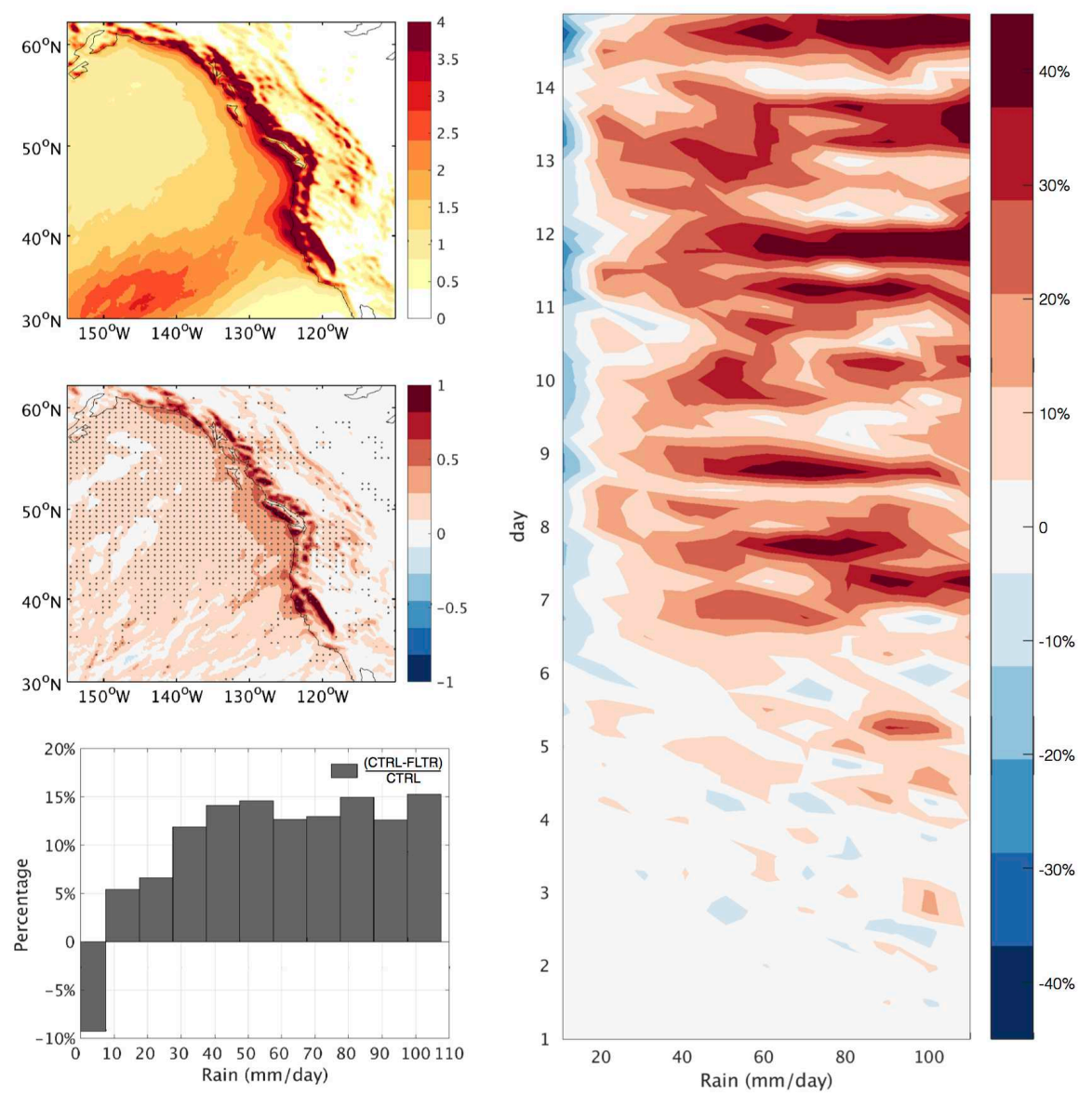

Figure 4 | Response of heavy precipitation along west coast of North America to mesoscale SST forcing in the cyclone ensemble. Two-week mean heavy precipitation (mm day ${ }^{-1}$ ) associated with landfalling ARs in CE CTRL (a) and the corresponding difference between CE CTRL and FILT (b). Two-week mean (c) and time evolving (d) PDF of relative difference of 6-hourly precipitation (averaged in the magenta box in Fig. 1c) concurrent with landfalling ARs between CE CTRL and FILT in reference to CE CTRL. The mean precipitation is computed as the sum of landfalling AR induced precipitation over the heavy precipitation days divided by the two-week simulation period. The difference above $95 \%$ confidence level based on a two-sided student $t$-test is shaded by gray dots. 

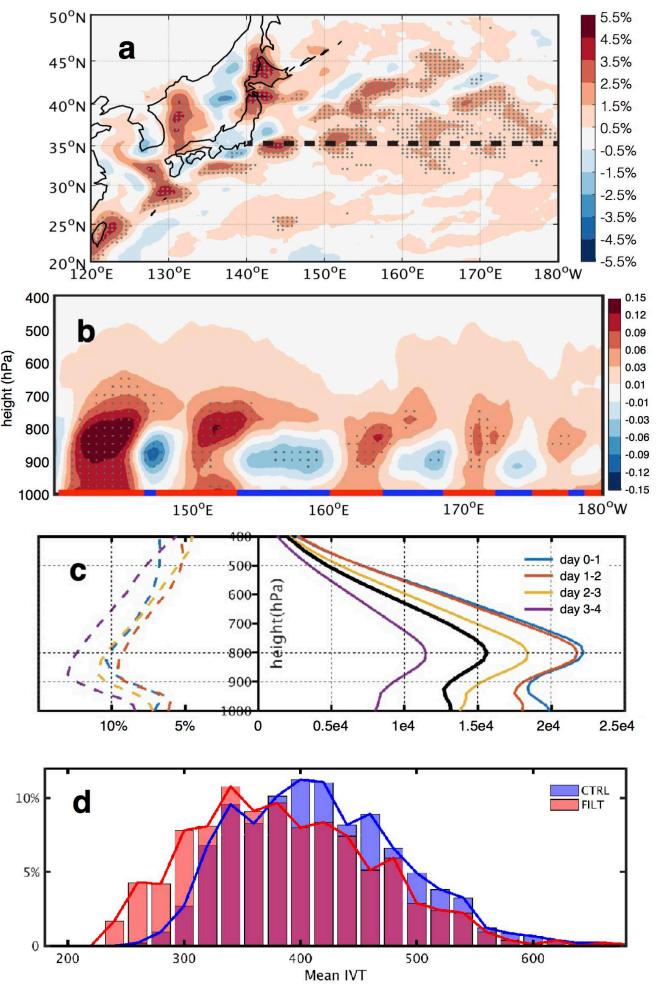
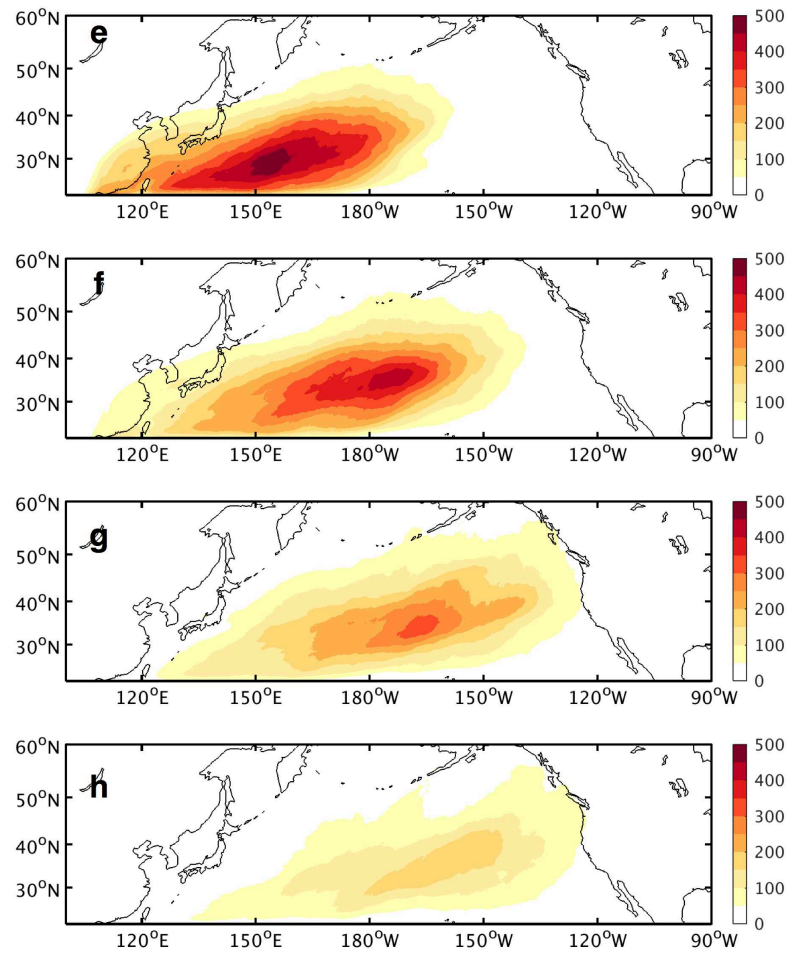

Figure 5 | Mechanism of Kuroshio mesoscale SST forcing ARs. Percentage difference of two-week mean water vapor mixing ratio (Q) at $800 \mathrm{hPa}$ between CE CTRL and FILT relative to CE CTRL (a). Difference of two-week mean water vapor mixing ratio $(\mathrm{Q}, \mathrm{kg} / \mathrm{kg})$ along the Kuroshio extension (dashed line in a) between CE CTRL and FILT (b). The heavy line at the bottom of (b) indicates warm (red) and cold (blue) mesoscale SST anomalies. Vertical profile of daily-mean Q anomalies $(\mathrm{kg} / \mathrm{kg})$ carried by all the ARs within each daily interval, 0-1 day (blue), 1-2 day (red), 2-3 day (yellow) and 3-4 day (purple) following ARs' evolution in CE CTRL (solid lines) and the corresponding fractional difference between CE CTRL and FILT relative to CE CTRL (dashed lines) (c). The thick black line shows the vertical profile of daily mean Q anomalies carried by all ARs detected in ERA5 averaged over 10 boreal winter seasons (NDJFM) from 2008 to 2017. PDFs of ARs when they are first formed in CE CTRL (blue) and FILT (red) (d). Daily mean IVT $\left(\mathrm{kg} \cdot \mathrm{m}^{-1} \mathrm{~s}^{-1}\right)$ of all ARs detected within each daily interval, 0-1 day (e) , 1-2 day (f), 2-3 day (g) and 3-4 day (h) following ARs' evolution in CE CTRL. The daily mean values in (c) and (e-h) are all derived from 6-hourly model output. The daily mean $\mathrm{Q}$ anomalies in (c) are computed as the sum of area accumulated Q anomalies within ARs detected on corresponding days divided by the total number of corresponding days. The daily mean IVT in (e-h) is computed as the sum of IVT of all ARs detected on corresponding days divided by the total number of corresponding days. The difference above $95 \%$ confidence level based on a two-sided student t-test is shaded by gray dots. 

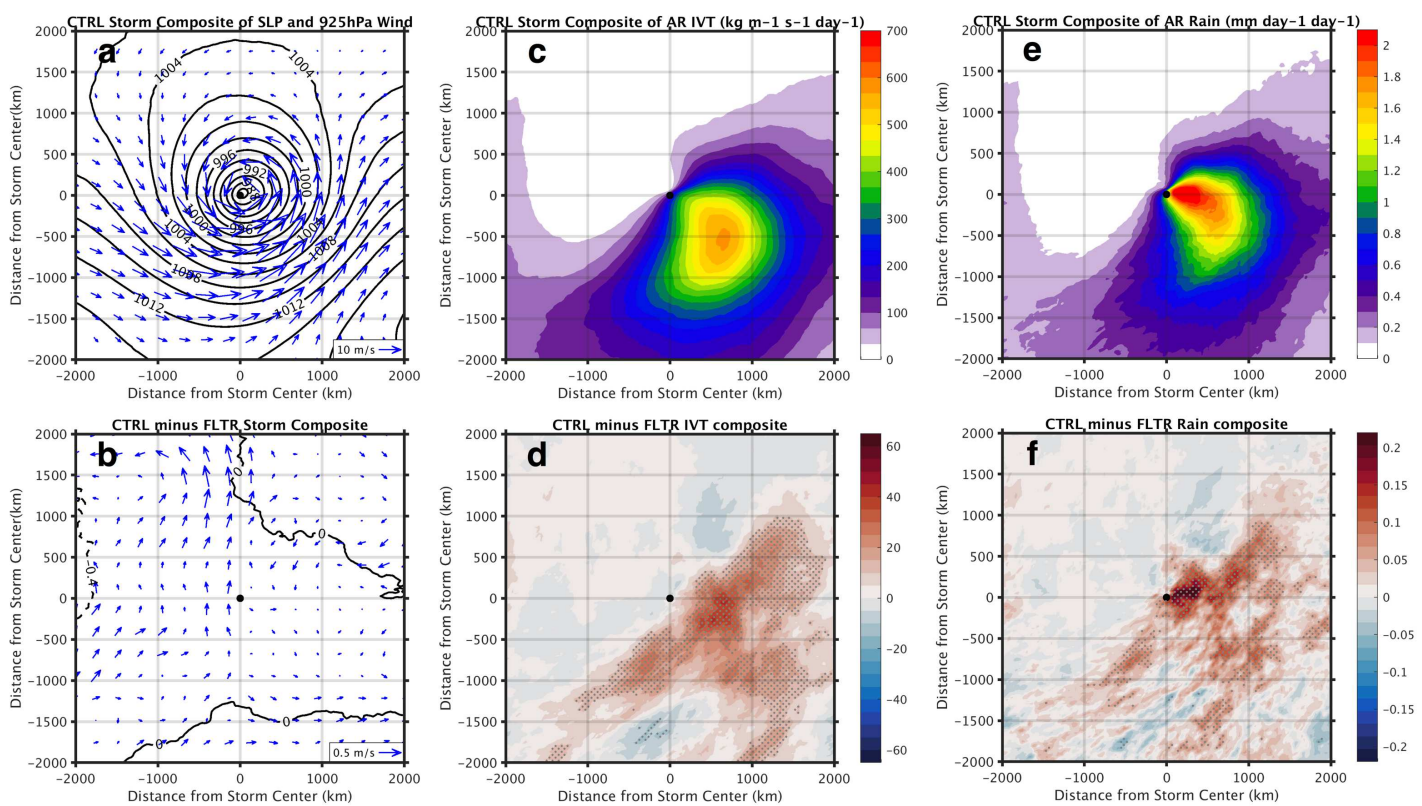

Figure 6 | Composite of extratropical cyclones in the cyclone ensemble experiment.

Composite of SLP (contours, $\mathrm{hPa}$ ) and $925 \mathrm{hPa}$ wind (vector, $\mathrm{ms}^{-1}$ ) of all identified extratropical cyclones in CE CTRL (a), and the corresponding differences between CE CTRL and FILT (b). The black dot indicates the center of composite cyclone. $\mathbf{c}$ and $\mathbf{d}$, same as $\mathbf{a}$ and $\mathbf{b}$, but for composite of AR IVT $\left(\mathrm{kg} \cdot \mathrm{m}^{-1} \mathrm{~s}^{-1}\right)$ associated with extratropical cyclones. e and $\mathbf{f}$, same as $\mathbf{a}$ and $\mathbf{b}$, but for composite of AR-induced precipitation (mm day $^{-1}$ ). The difference above $95 \%$ confidence level based on a two-sided student t-test is shaded by gray dots. 


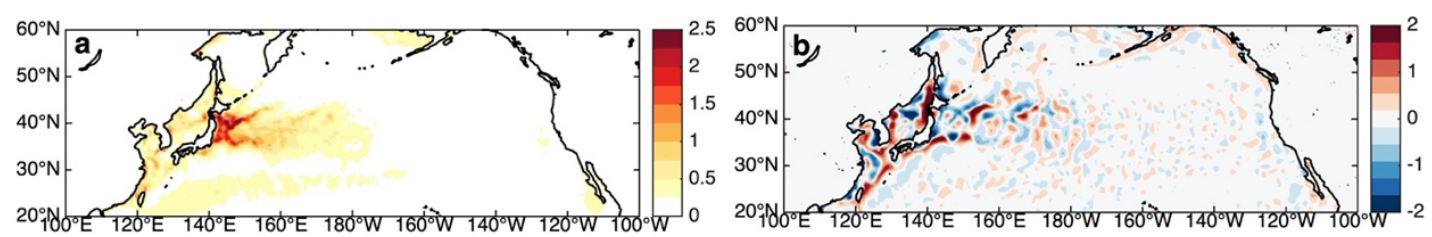

Extended Data Figure 1 | Mesoscale SST forcing in SE and CE simulations. Variance of SST $\left({ }^{\circ} \mathrm{C}^{2}\right)$ difference between SE CTRL and FILT for all 13 winter seasons (2002-2014 NDJFM) (a). Mean SST $\left({ }^{\circ} \mathrm{C}\right)$ difference between CE CTRL and FILT for all 568 cyclone cases (b). 


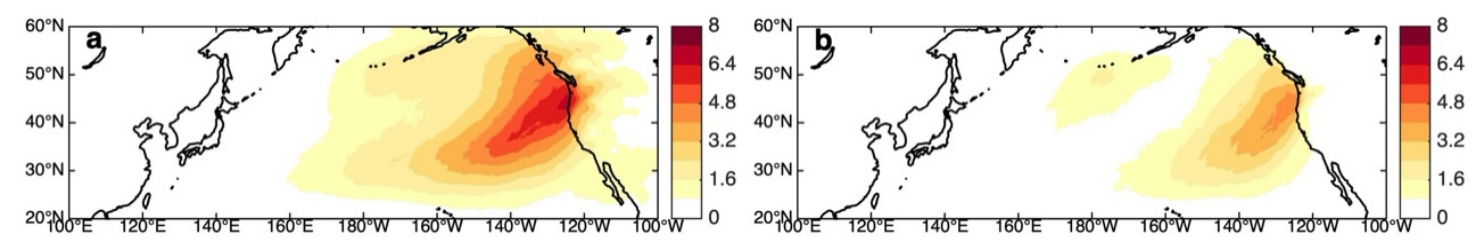

759 Extended Data Figure 2 | Simulated and observed landfalling ARs occurrence

frequency. Frequency (\%) of landfalling ARs in SE CTRL (a) and in ERA5 (1979-2017) during boreal winter season (NDJFM) (b). The frequency is defined as the number of days when landfalling ARs occur divided by the total number of winter season days. 

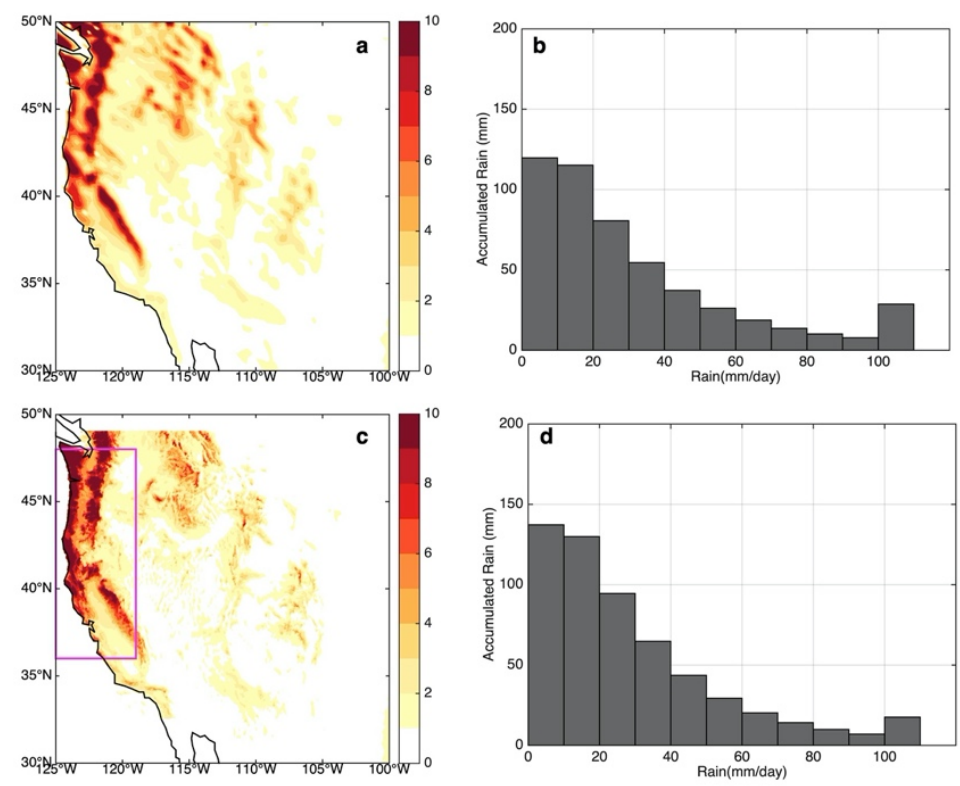

Extended Data Figure 3 | Simulated and observed winter precipitation over the western US. Winter season mean (NDJFM) precipitation (mm day $\left.{ }^{-1}\right)$ in SE CTRL (a) and in PRISM (1981-2017) (b). Daily precipitation PDFs (averaged in the magenta box in Extended Fig. 3c) in SE CTRL (c) and in PRISM (d). 

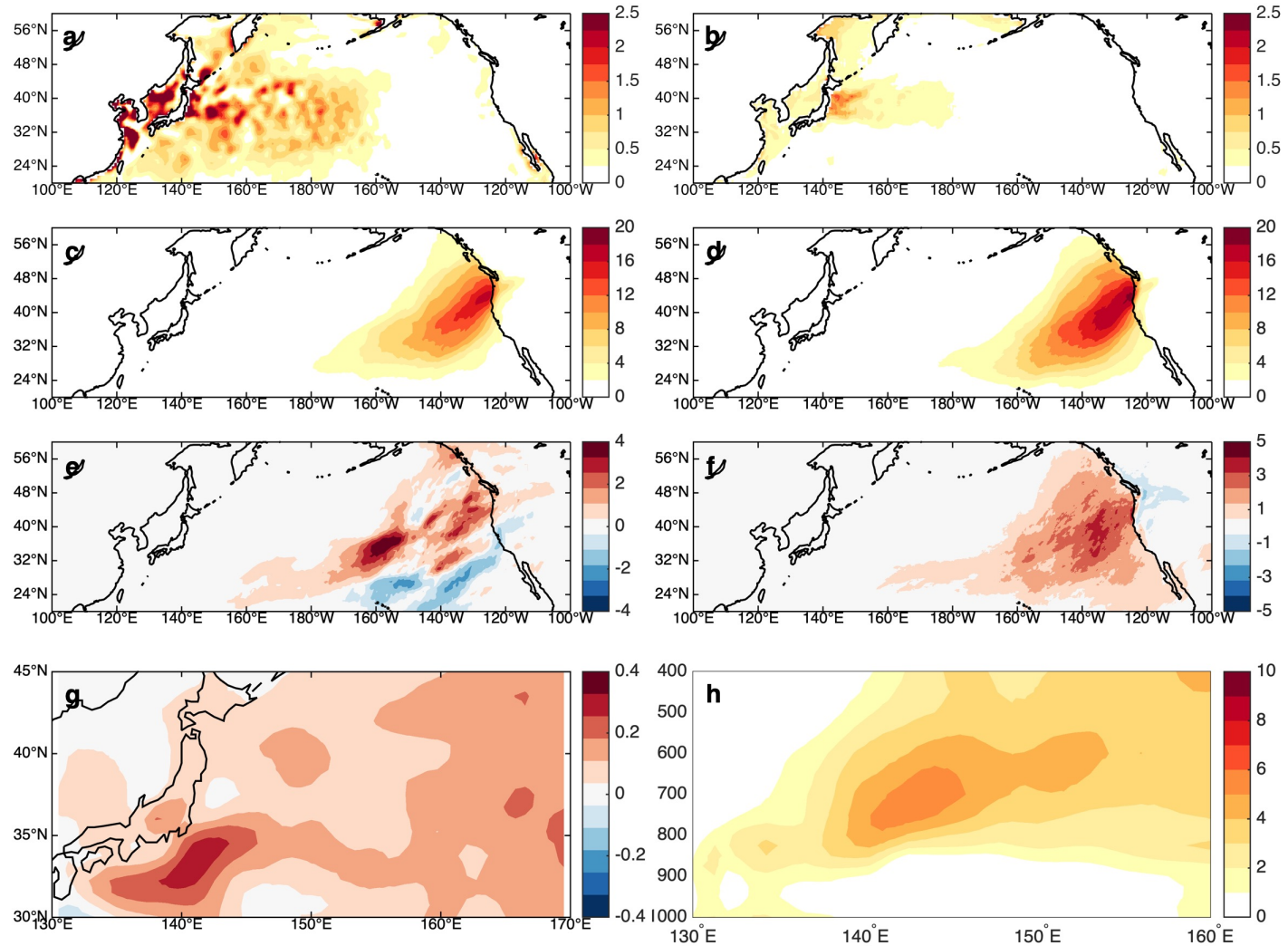

Extended Data Figure 4 | Response of landfalling ARs and water vapor to mesoscale

SST forcing in ERA-Interim and ERA5. Variance of SST $\left({ }^{\circ} \mathrm{C}^{2}\right)$ difference between the $0.5^{\circ}$-and-finer SST forcing period (2002-2017) and the $1^{\circ} \mathrm{SST}$ forcing period (1986-2001) in ERA-Interim (a). Accumulated IVT $\left(\mathrm{kg} \cdot \mathrm{m}^{-1} \mathrm{~s}^{-1}\right)$ associated with landfalling ARs averaged in winter season (NDJFM) during the high-resolution SST forcing period (20022017) (c) and the corresponding difference between high-resolution SST forcing period (2002-2017) and low-resolution SST forcing period (1986-2001) in ERA-Interim (e). b, d, f, as for a, $\mathbf{c}, \mathbf{e}$, but for the difference between ERA5, where higher resolution $\left(0.25^{\circ}\right) \mathrm{SST}$ forcing was used, and ERA-Interim during the period of 1979-2006. Difference of Q $(\mathrm{g} / \mathrm{kg})$ at $800 \mathrm{hPa}(\mathrm{g})$ and fractional difference of Q (\%) along a vertical section of the $\mathrm{KE}\left(35^{\circ} \mathrm{N}\right)$ (h) between high-resolution SST forcing period (2002-2017) and low-resolution SST forcing period (1986-2001) in ERA-Interim. Landfalling AR IVT in c-f is computed as the sum of IVT associated with landfalling ARs divided by the total number of all winter season days in ERA-Interim and ERA5, respectively. 

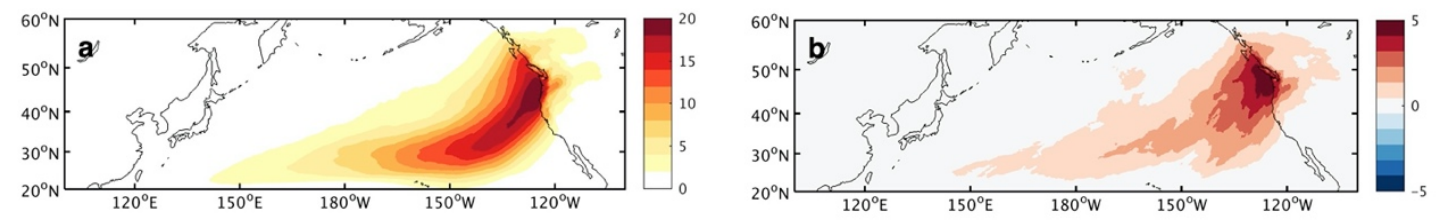

787 Extended Data Figure 5 | Response of heavy precipitation associated landfalling ARs to mesoscale SST forcing in the cyclone ensemble experiment. Landfalling AR IVT $\left(\mathrm{kg} \cdot \mathrm{m}^{-1} \mathrm{~s}^{-1}\right)$ accumulated over the heavy precipitation days averaged over the two-week period in CE CTRL (a) and the corresponding difference between CE CTRL and FILT (b). Landfalling AR IVT is calculated the same as that in Fig. 2a. 


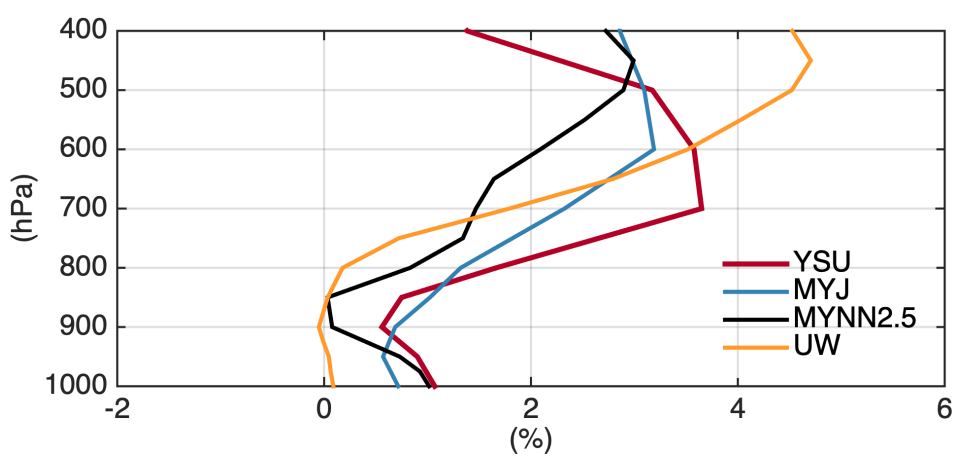

Extended Data Figure 6 | Sensitivity of Water Vapor Response to Different PBL and

Surface Layer Schemes in WRF Sensitivity Ensemble Simulations. Fractional difference (\%) of the vertical profile of winter season mean (NDJFM) Q averaged in AR genesis region $\left(\left[25^{\circ} \mathrm{N}-35^{\circ} \mathrm{N} 130^{\circ} \mathrm{E}-150^{\circ} \mathrm{E}\right]\right)$ between CTRL and FILT in reference to CTRL of WRF sensitivity experiments with different PBL and surface layer schemes. All the results are based on the ensemble mean of 10 2007/8 winter-season runs in each sensitivity experiment.

802 

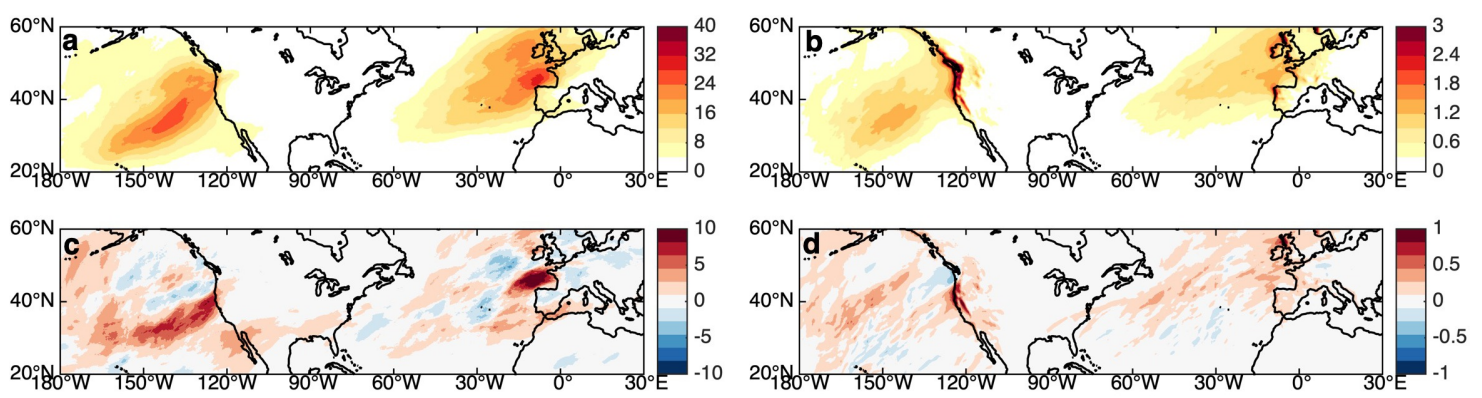

Extended Data Figure 7 | Response of landfalling ARs to mesoscale SST forcing from global CAM ensemble simulations. Averaged IVT $\left(\mathrm{kg} \cdot \mathrm{m}^{-1} \mathrm{~s}^{-1}\right)$ associated with landfalling ARs in boreal winter months (DJF) in the CTRL (a) and the corresponding difference between the CTRL and FILT (c). b and $\mathbf{d}$, same as a and $\mathbf{c}$, but for precipitation (mm day${ }^{1}$ ). Averaged IVT (precipitation) is computed as the sum of IVT (precipitation) associated with landfalling ARs divided by the total number of winter month days in global CAM ensemble. 


\section{Figures}
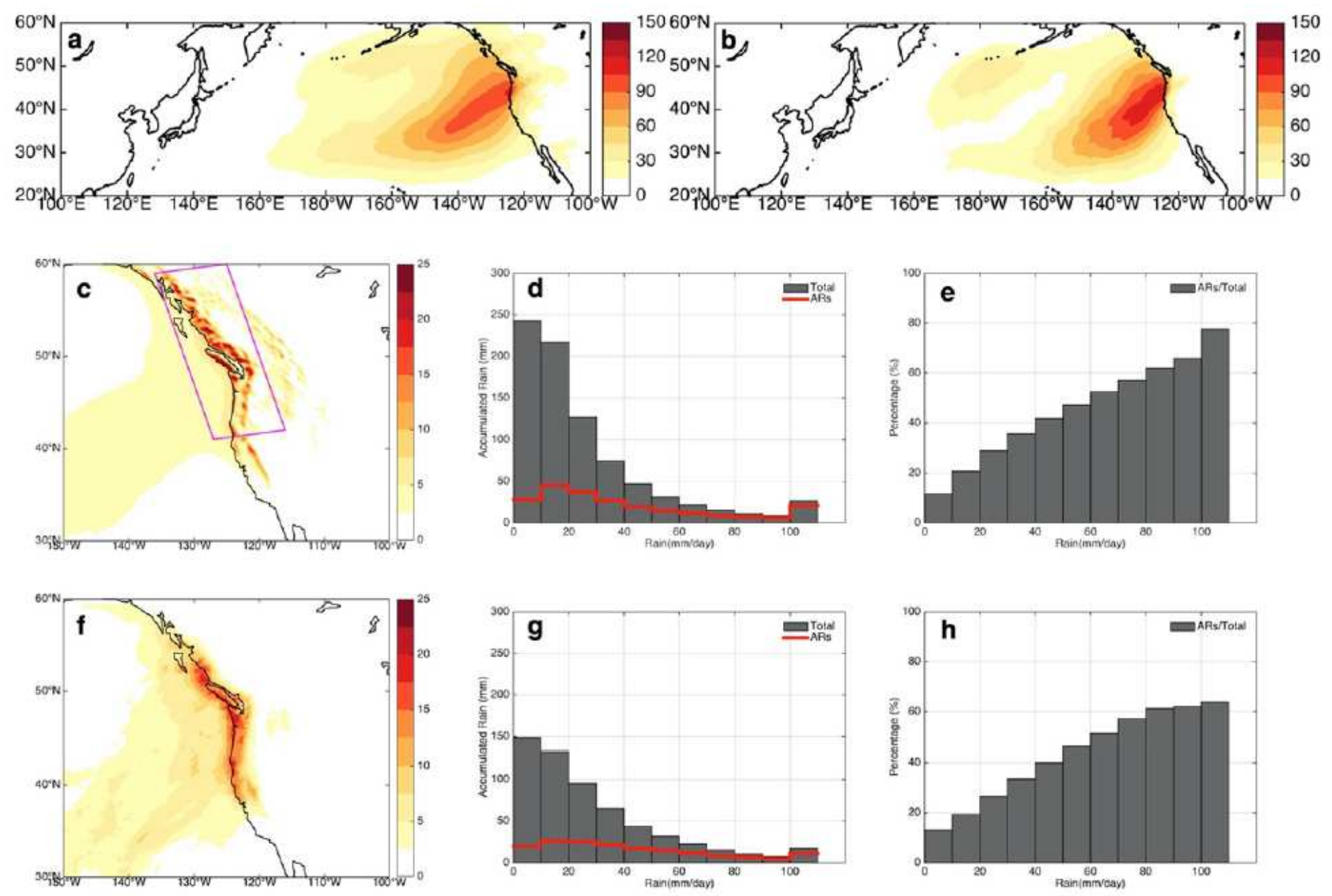

\section{Figure 1}

Landfalling ARs and concurrent precipitation along the west coast of North America. Averaged IVT (kg $\times \mathrm{m}-1 \mathrm{~s}-1)$ associated with landfalling ARs simulated in SE CTRL (a) and in ERA5 (1979-2017) (b) during the winter season (NDJFM). Averaged precipitation (mm day-1) associated with landfalling ARs simulated in SE CTRL (c) and in GPM (2014-2016) (f) during the winter season (NDJFM). PDFs of daily precipitation (averaged in the magenta box in Fig. 1c) for all precipitation events (histogram) and those concurrent with landfalling ARs (red line) in SE CTRL (d) and in GPM (g), respectively. PDFs of fraction contribution (\%) of AR-related precipitation to total precipitation in SE CTRL (e) and in GPM (h), respectively. Averaged IVT (precipitation) is computed as the sum of IVT (precipitation) associated with landfalling ARs divided by the total number of landfalling ARs days. 

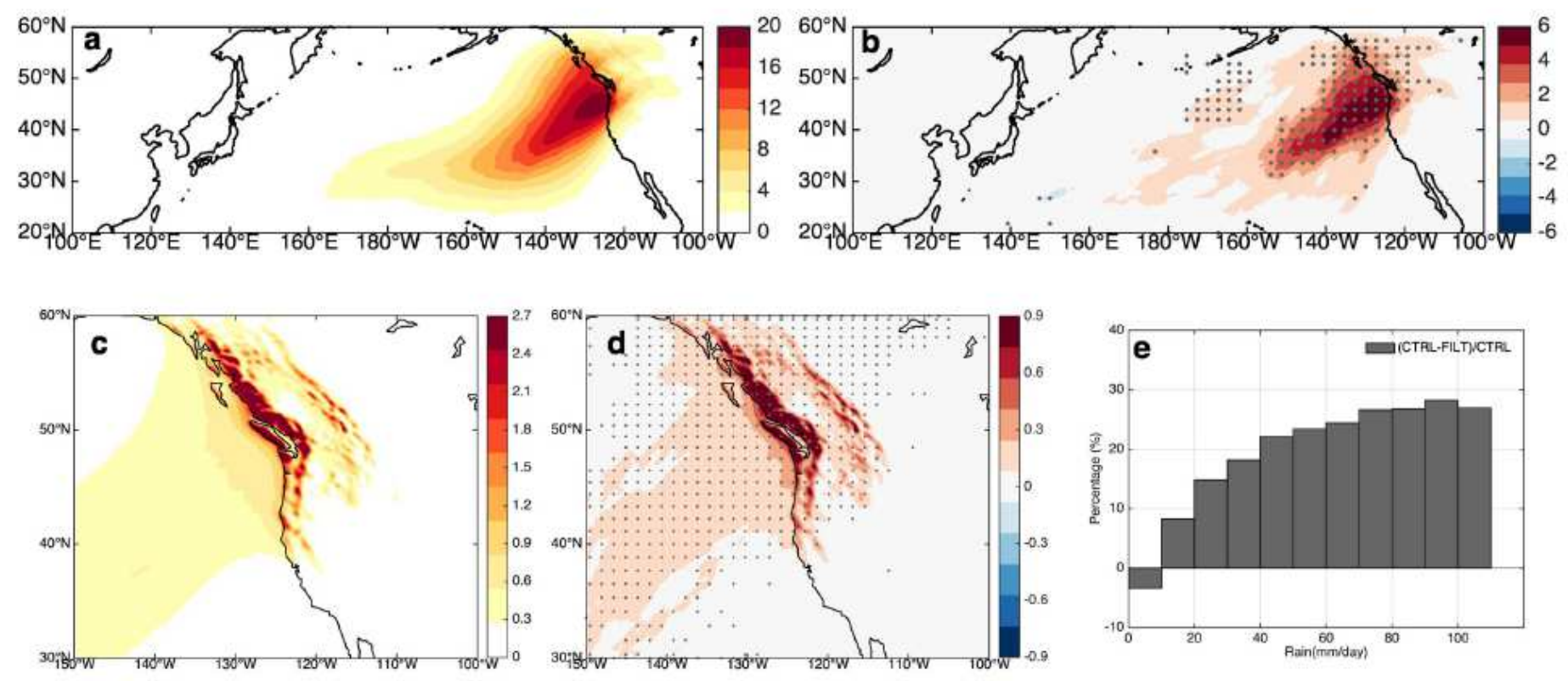

Figure 2

Response of landfalling ARs and heavy precipitation to mesoscale SSTs in the seasonal ensemble experiment. Landfalling AR IVT ( $\mathrm{kg} \times \mathrm{m}-1 \mathrm{~s}-1)$ summed over the heavy precipitation days and then divided by the total number of days (150x65) in SE CTRL (a) and the corresponding difference between SE CTRL and FILT (b). $c$ and d, same as a and b, but for precipitation ( $m m$ day-1). PDF of relative difference of precipitation concurrent with landfalling ARs between SE CTRL and FILT in reference to SE CTRL (the red curve in Fig. 1) (e). Heavy precipitation events are defined as area-averaged (magenta box in Fig. 1c) daily precipitation events exceeding the 75th percentile of the value. The difference above $95 \%$ confidence level based on a two-sided student t-test is shaded by gray dots. 

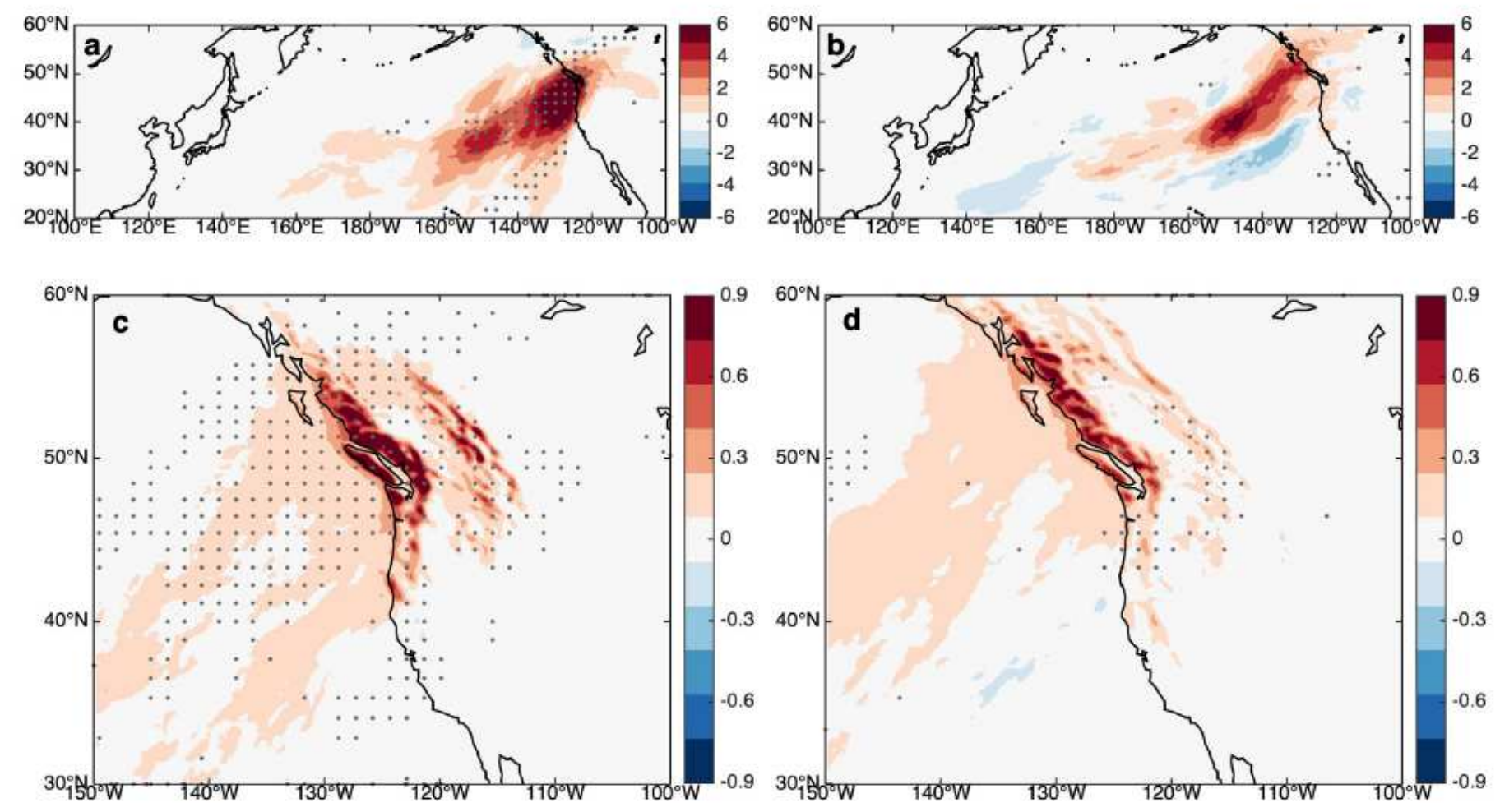

\section{Figure 3}

Relationship between ARs/precipitation response strength and SST forcing strength in the seasonal ensemble. a and c, same as Fig. 2b and 2d, but for four strong mesoscale SST forcing cases. b and d, same as Fig. $2 b$ and $2 d$, but for four weak mesoscale SST forcing cases. 

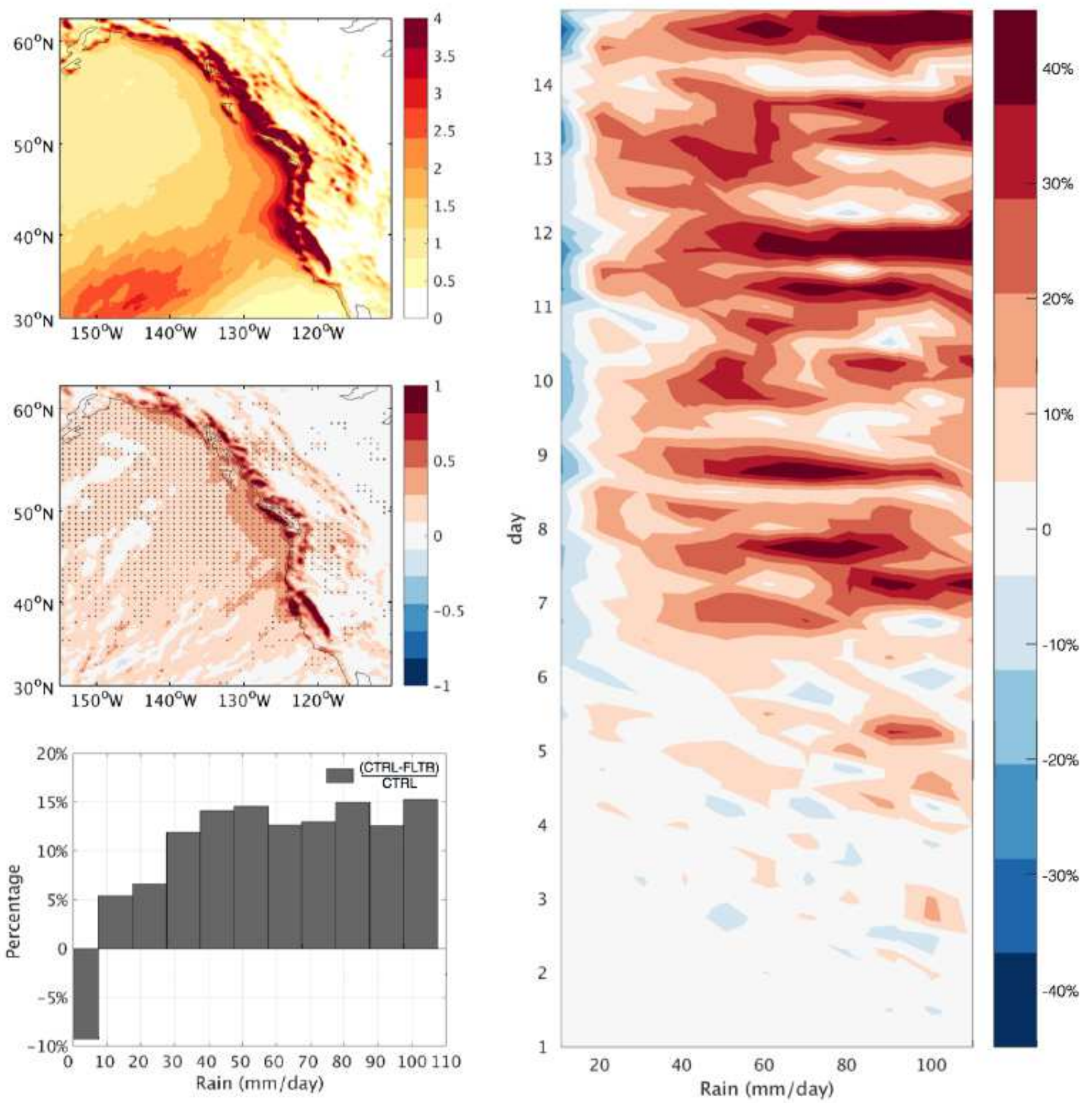

\section{Figure 4}

Response of heavy precipitation along west coast of North America to mesoscale SST forcing in the cyclone ensemble. Two-week mean heavy precipitation ( $\mathrm{mm}$ day-1) associated with landfalling ARs in CE CTRL (a) and the corresponding difference between CE CTRL and FILT (b). Two-week mean (c) and time evolving (d) PDF of relative difference of 6-hourly precipitation (averaged in the magenta box in Fig. 1c) concurrent with landfalling ARs between CE CTRL and FILT in reference to CE CTRL. The mean precipitation is computed as the sum of landfalling AR induced precipitation over the heavy precipitation 
days divided by the two-week simulation period. The difference above $95 \%$ confidence level based on a two-sided student t-test is shaded by gray dots.
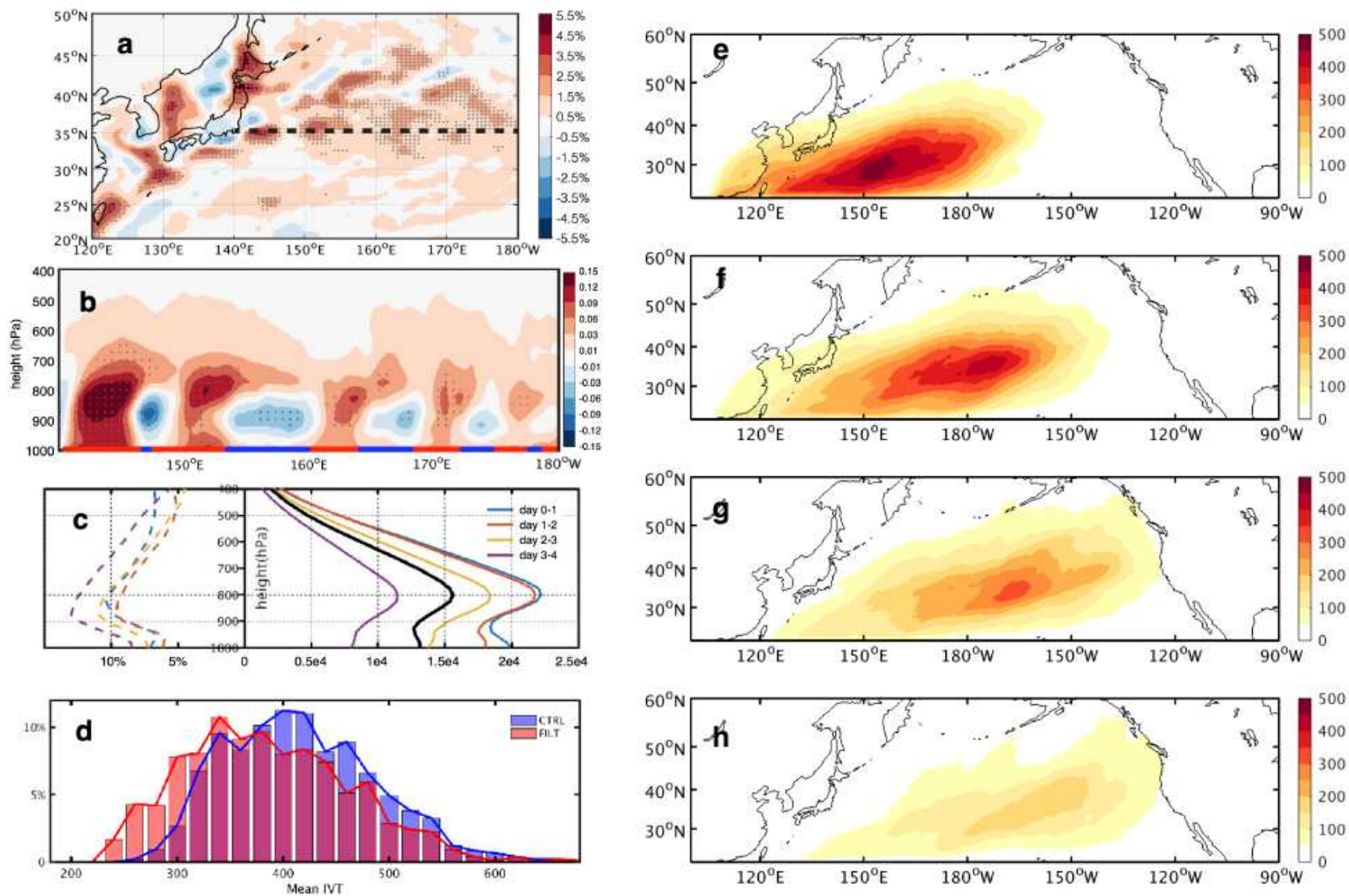

\section{Figure 5}

Mechanism of Kuroshio mesoscale SST forcing ARs. Percentage difference of two-week mean water vapor mixing ratio (Q) at $800 \mathrm{hPa}$ between CE CTRL and FILT relative to CE CTRL (a). Difference of twoweek mean water vapor mixing ratio $(\mathrm{Q}, \mathrm{kg} / \mathrm{kg}$ ) along the Kuroshio extension (dashed line in a) between CE CTRL and FILT (b). The heavy line at the bottom of (b) indicates warm (red) and cold (blue) mesoscale SST anomalies. Vertical profile of daily-mean Q anomalies $(\mathrm{kg} / \mathrm{kg})$ carried by all the ARs within each daily interval, 0-1 day (blue), 1-2 day (red), 2-3 day (yellow) and 3-4 day (purple) following ARs' evolution in CE CTRL (solid lines) and the corresponding fractional difference between CE CTRL and FILT relative to CE CTRL (dashed lines) (c). The thick black line shows the vertical profile of daily mean $Q$ anomalies carried by all ARs detected in ERA5 averaged over 10 boreal winter seasons (NDJFM) from 2008 to 2017. PDFs of ARs when they are first formed in CE CTRL (blue) and FILT (red) (d). Daily mean IVT (kg $\times \mathrm{m}-1 \mathrm{~s}-1)$ of all ARs detected within each daily interval, 0-1 day (e), 1-2 day (f), 2-3 day (g) and 3-4 day (h) following ARs' evolution in CE CTRL. The daily mean values in (c) and (e-h) are all derived from 6 -hourly model output. The daily mean $Q$ anomalies in (c) are computed as the sum of area accumulated $Q$ anomalies within ARs detected on corresponding days divided by the total number of corresponding days. The daily mean IVT in (e-h) is computed as the sum of IVT of all ARs detected on corresponding days divided by the total 
number of corresponding days. The difference above $95 \%$ confidence level based on a two-sided student t-test is shaded by gray dots.
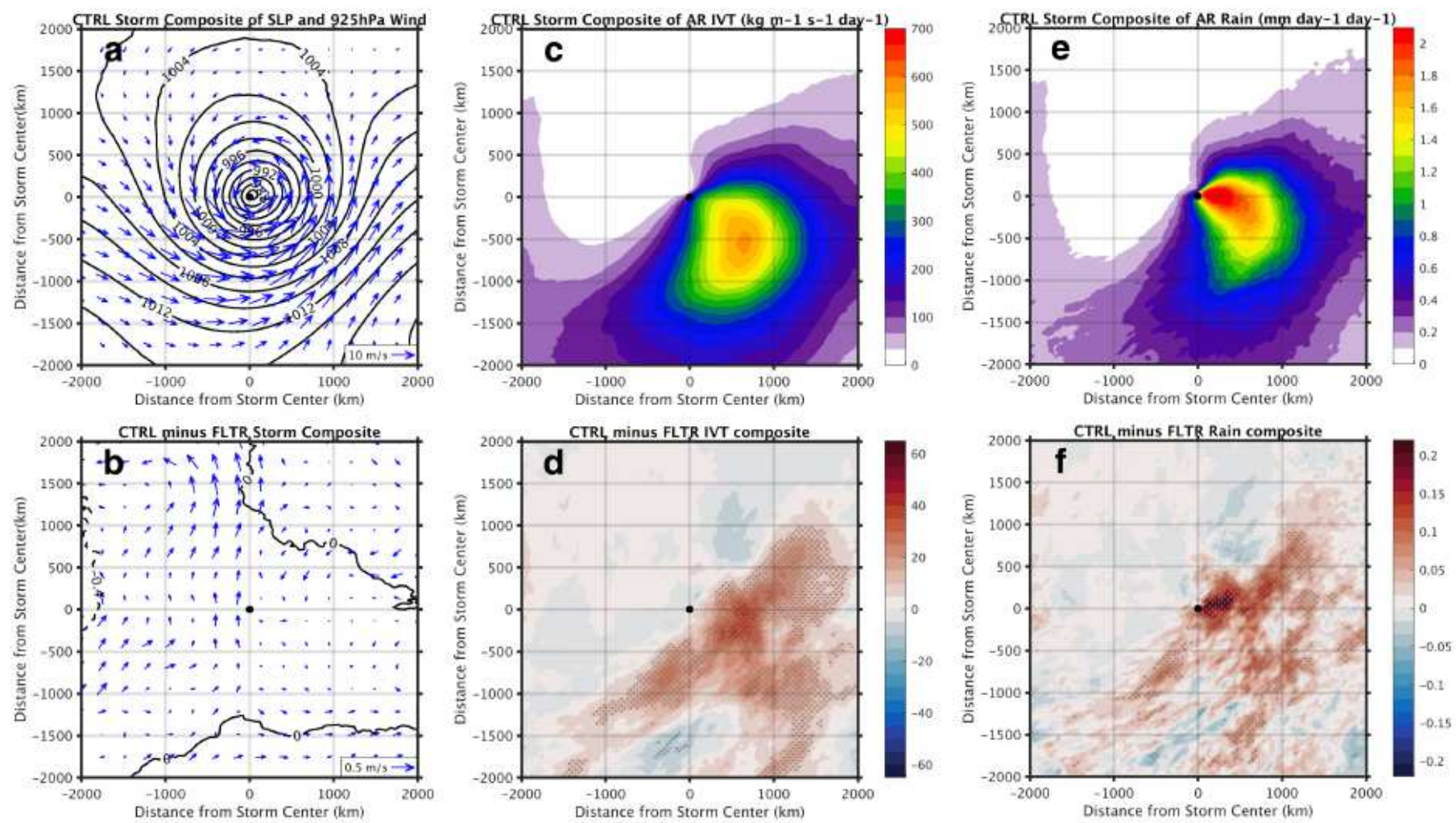

Figure 6

Composite of extratropical cyclones in the cyclone ensemble experiment. Composite of SLP (contours, $\mathrm{hPa}$ ) and $925 \mathrm{hPa}$ wind (vector, ms-1) of all identified extratropical cyclones in CE CTRL (a), and the corresponding differences between CE CTRL and FILT (b). The black dot indicates the center of composite cyclone. $c$ and $d$, same as $a$ and $b$, but for composite of AR IVT (kg $\times m-1 s-1)$ associated with extratropical cyclones. e and $\mathrm{f}$, same as $\mathrm{a}$ and $\mathrm{b}$, but for composite of AR-induced precipitation ( $\mathrm{mm}$ day1). The difference above $95 \%$ confidence level based on a two-sided student $t$-test is shaded by gray dots. 